\title{
On the Occurrence of Upwelling in the Southern Makassar Strait
}

by

\author{
Abdul Gani Ilahude \\ INTRODUCTION
}

The possibility of upwelling occuring off the coast of Sulawesi in the Southern Makassar Strait has been discussed by earlier workers (see e.g. Veen 1953, and Wyrtki 1961). Surface salinity data show higher values in June or July along the southwest coast of Sulawesi than the rest area to the west of it. The months June and July coincide with the southeast monsoon in the area. It is believed that the presence of such high salinity could only be due to the process of upwelling. As already mentioned in these works (e.g. by Wyrtki, 1961) during the southeast monsoon, the west-going surface currents coming from the Northern Makassar Strait and the Flores Sea pass the area, and flow into the Java Sea. It is thought that part of the water masses transported by the currents originate from subsurface layer off Makassar coast.

\section{OBSERVATIONS AND DATA}

In 1965 the Institute for Marine Research (L. P. L.) in Djakarta planned two oceanographic cruises to investigate the upwelling in this area. One cruise was planned for February - March and the other for August - September, each was intended to coincide with the late period of the northwest and the southeast monsoon respectively. Because of the financial difficulties only the February - March cruise was carried out using the R.V. Jalanidhi. Fortunately the Dana and the Snellius Expeditions had made the August - September observations in the area in 1929 (Van Riel et al., 1950, Thomsen, 1935). Assuming that the oceanographic condition will be more or less the same in each season regardless of the year, it was decided to use these observations. All the stations of the cruises that are used in preparing the present paper are shown in Figure 1.

To get the additional information, the surface data in the L. P. L.'s file are also used. They are the surface salinity and temperature pertaining to the Southern Makassar Strait that have been collected by L. P. L. since its initiation by Veen in 1949. The method of securing, processing and filing the data is described in the papers of Veen $(1951,1953)$ and Soeriaatmadja (1956). In all there are 17428 salinity and 15148 temperature observations used. From these observations the monthly average values for each degree 


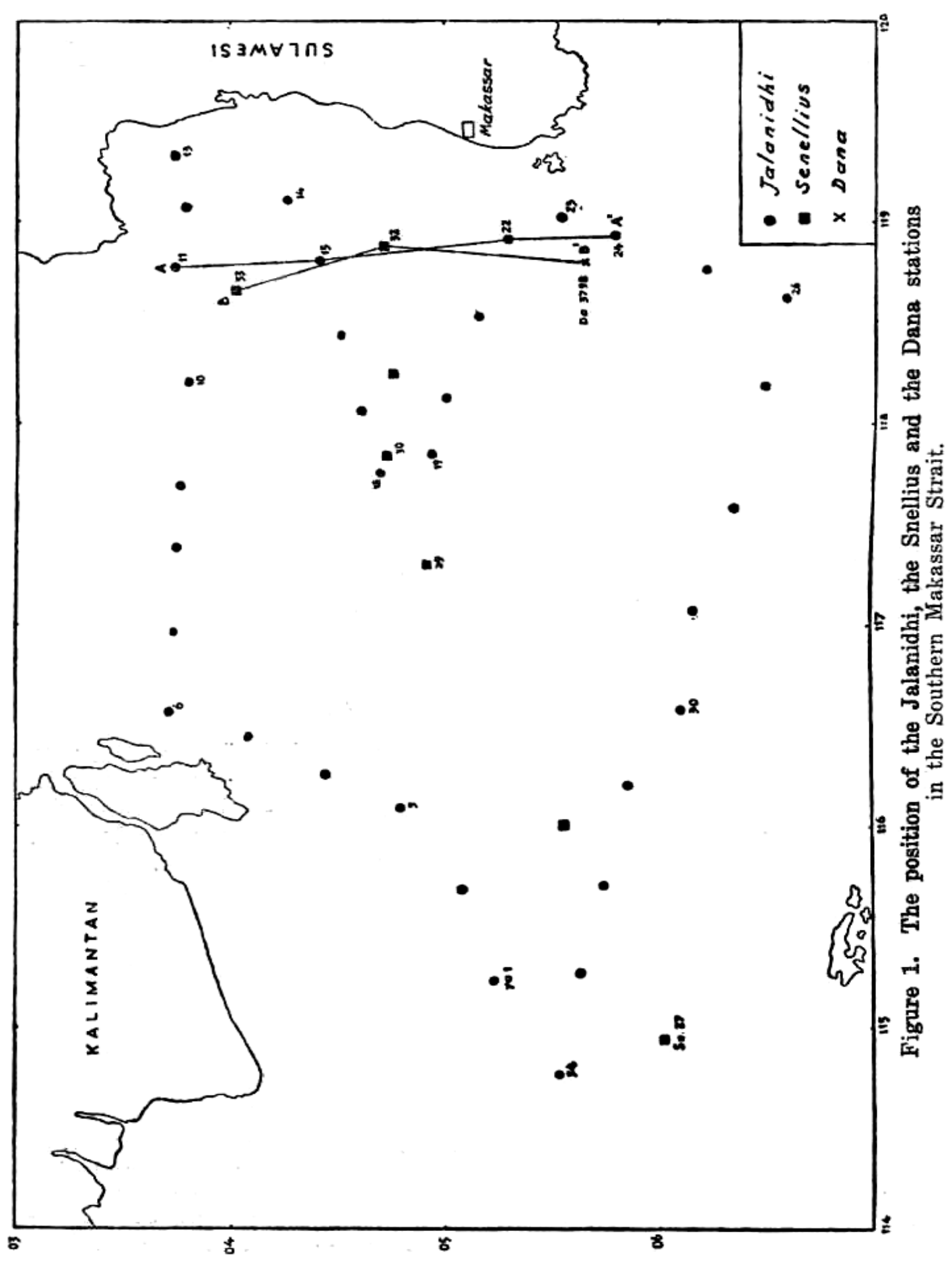




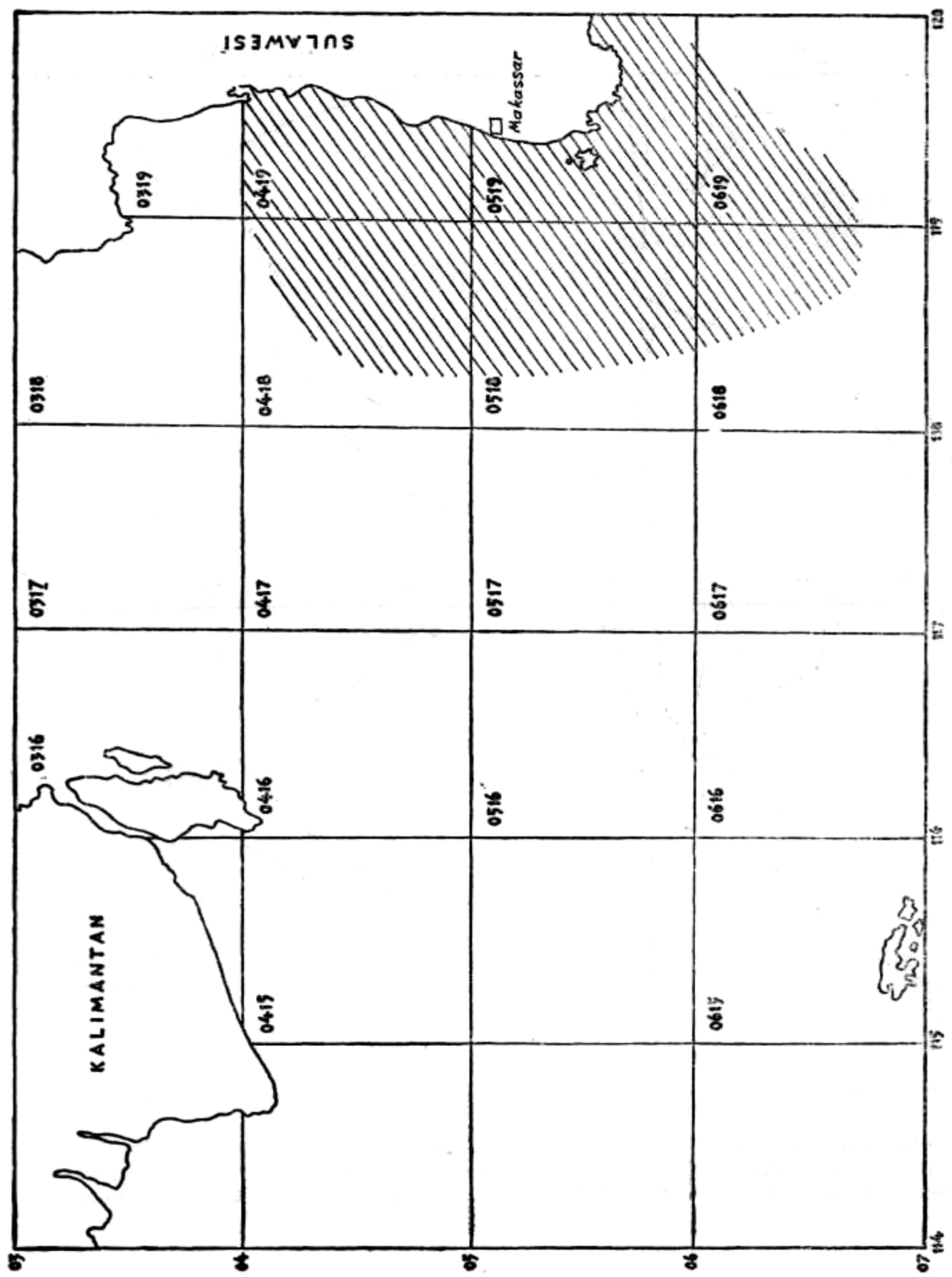

Figure 2. The number and area of the degree squares in the Southern Makassar Strait as is used in filing the salinity and temperature data at the L.P.L. Shaded areas show the approximate region of the upwelling. 


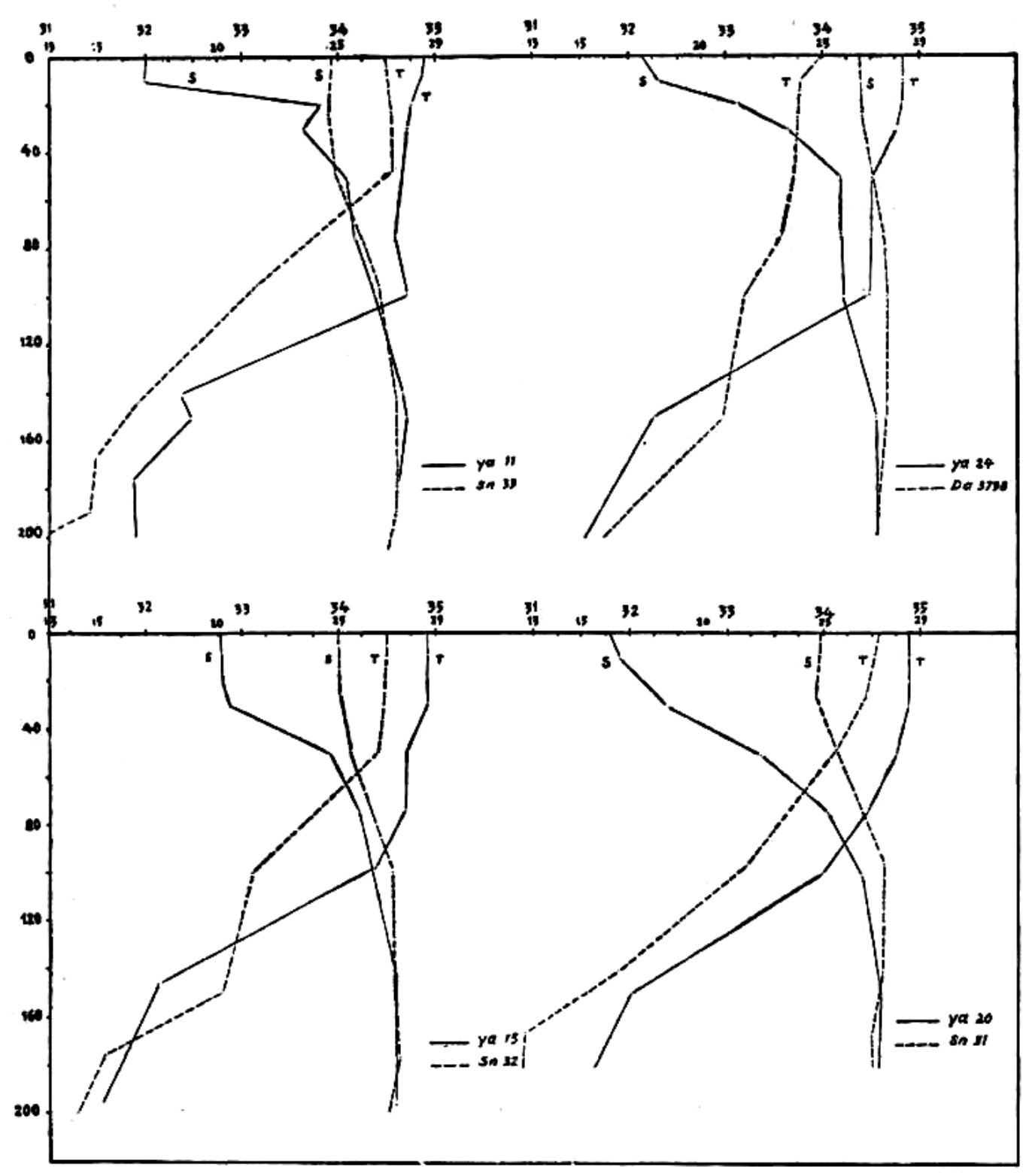

Figure 3. The vertical salinity and temperature profiles in the Southern Makassar Strait. The solid lines show the condition during the northwest monsoon and the dashed lines show the condition during the southeast monsoon. 


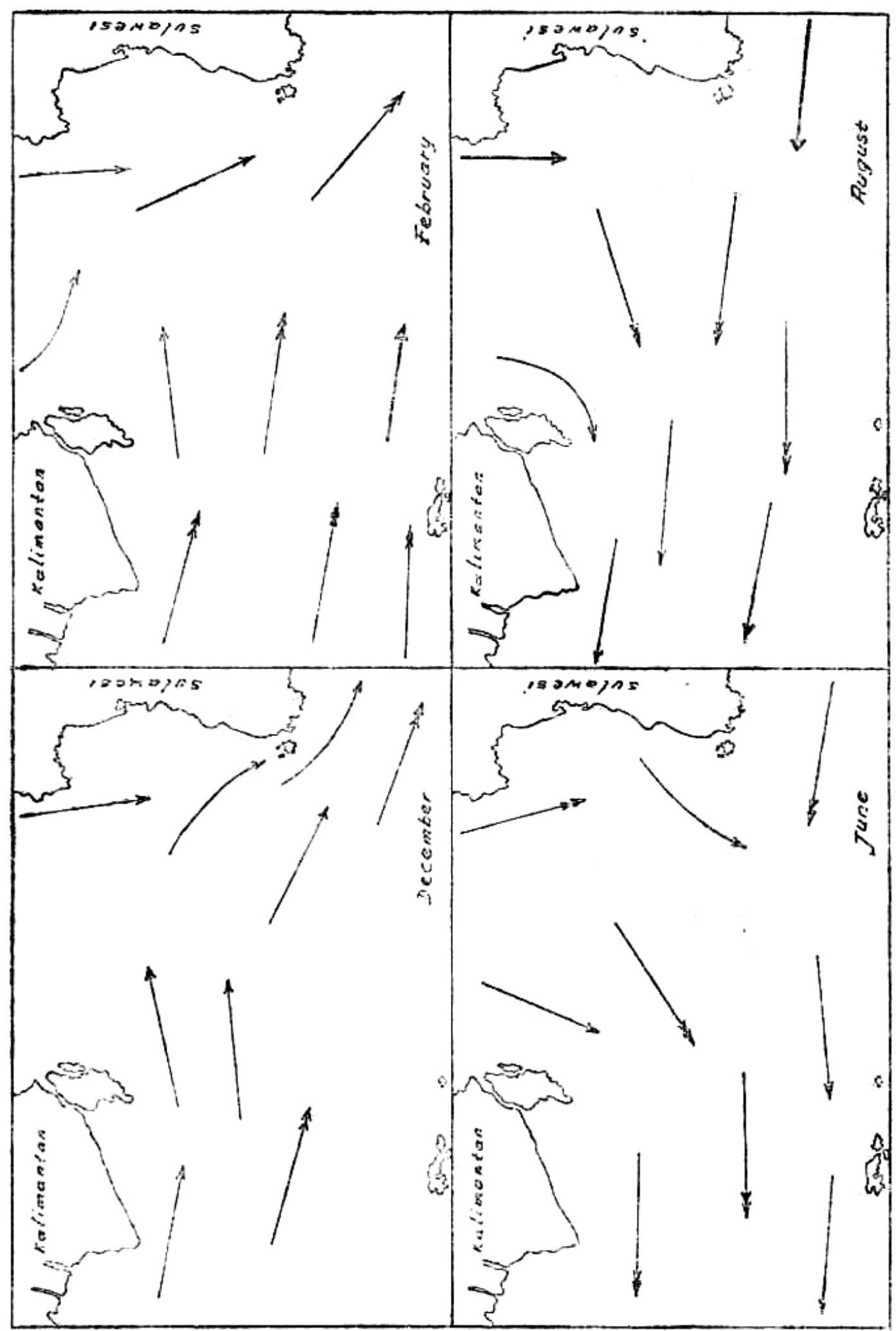

Figure 4. The seasonal current system in the Southern Makassar Strait according to Wyrtki (1957). 
square (totaling 18 squares) in each year were calculated. Then the monthly average values of the period 6 to 12 years (depending on the available observations) are in turn averaged to get the "normal" monthly values. They are tabulated in Table 1 and 2 and the area represented by each degree square is shown in Figure 2. In addition some of the inorganic phosphate data obtained in different cruises of Jalanidhi are also used. All the oceanographic data obtained by Jalanidhi during the period 1963 to 1966 have been compiled by the author (unpublished manuscript) and part of the phosphate data are tabulated in Table 3.

\section{OCCURRENCE OF UPWELLING}

Figure 3 shows the vertical profiles of temperature and salinity obtained during the Jalinidhi, the Snellius and the Dana cruises in the Southern Makassar Strait at the stations numbering Ja 11, 15, 20, 24, Sn 31, 32, 33 and Da 3798. All of these stations are in front of the coast of Makassar (see Figure 1). It can be seen that in February - March a surface layer of homogeneous temperature about $100 \mathrm{~m}$ thick is present in the area. In August - September the layer become thinner amounting to about $50 \mathrm{~m}$, which in this particular region means also that the thermocline rises as much as $50 \mathrm{~m}$. It is seen further that the temperature of the homogeneous layer decreases while its salinity increases. A similar phenomenon was reported by Wyrtki (1958) for the Banda Sea, which he pointed out to be due to the process of upwelling. For the case of the Southern Makassar Strait the upwelling seems also to be the best explanation for this phenomenon. As already discussed by Wyrtki (1961) it is the current system in the area that causes it. Figure 4 shows the surface current in the Southern Makassar Strait during the southeast monsoon (June, August) and the northwest monsoon (December, February) according to Wyrtki $(1957,1961)$. During the southeast monsoon water masses from the Flores Sea meet here with water coming out of the Makassar Srait and flow together into the Java Sea. Under these conditions it is possible that immediately off the coast of Makassar the water masses of the surface are integrated into this flow and water from deeper layers ascends.

Due to the lack of data the question of how exactly the upwelling occurs in this area can only be discussed in a general way. Figure 5 and Figure 6 show the cross section of temperature and salinity based on the Jalanidhi and Snellius stations along the line $\mathrm{AA}^{\prime}$ and $\mathrm{BB}^{\prime}$ of Figure 1. They show first of all the different water masses present in this area. Their distribution has been discussed by various workers (e.g. Postma, 1958, and Wyrtki, 1961). They are the Homogeneous Surface Layer which thickness fluctuates seasonally between 0 to $100 \mathrm{~m}$ in February and 0 to $50 \mathrm{~m}$ in August. The 27 ${ }^{\circ} \mathrm{C}$ isotherm can be regarded as its lower boundary. Below this the 

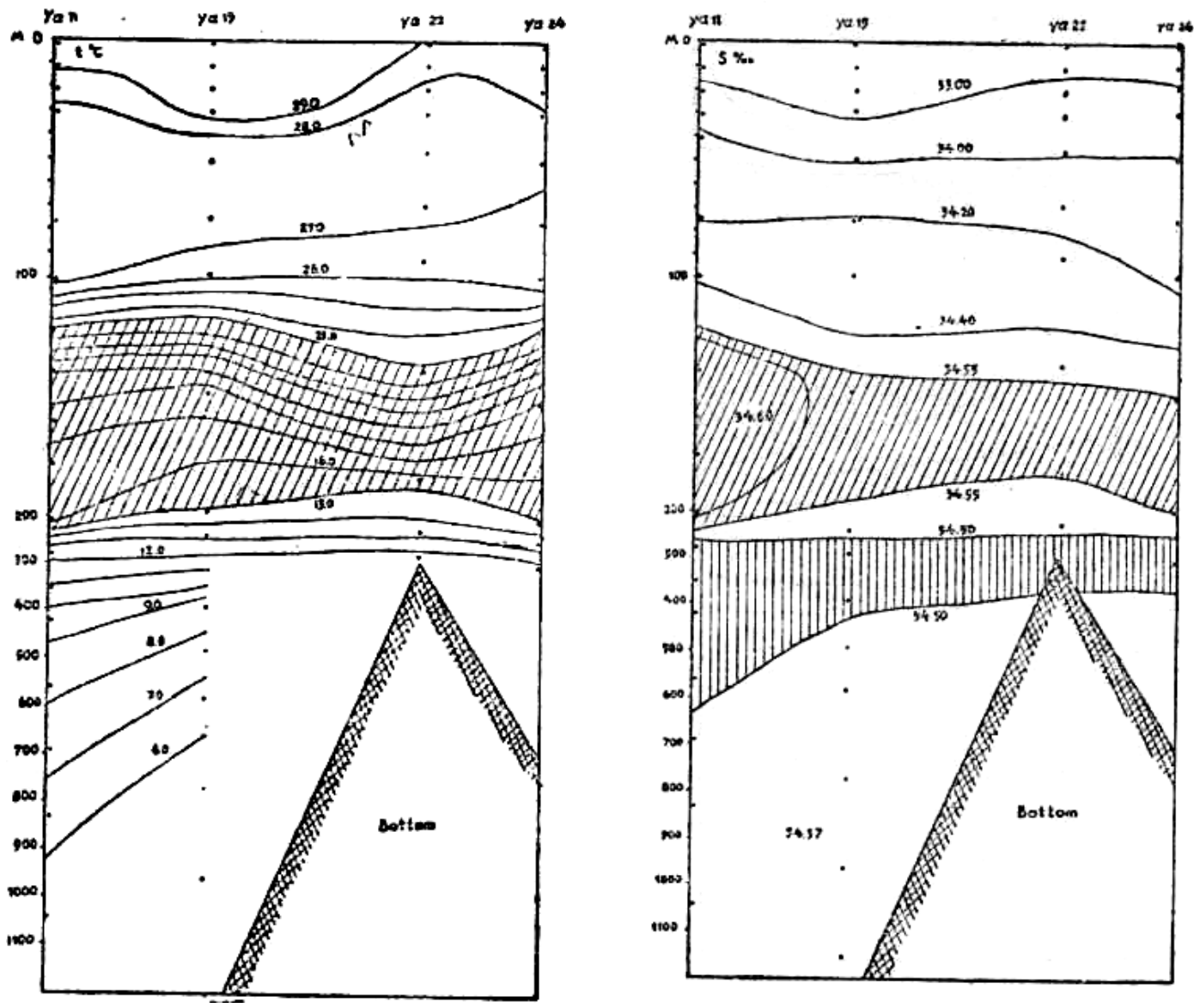

Figure 5. The cross section of temperature and salinity off Makassar coast along the line AA' Figure 1 during the northwest monsoon. 

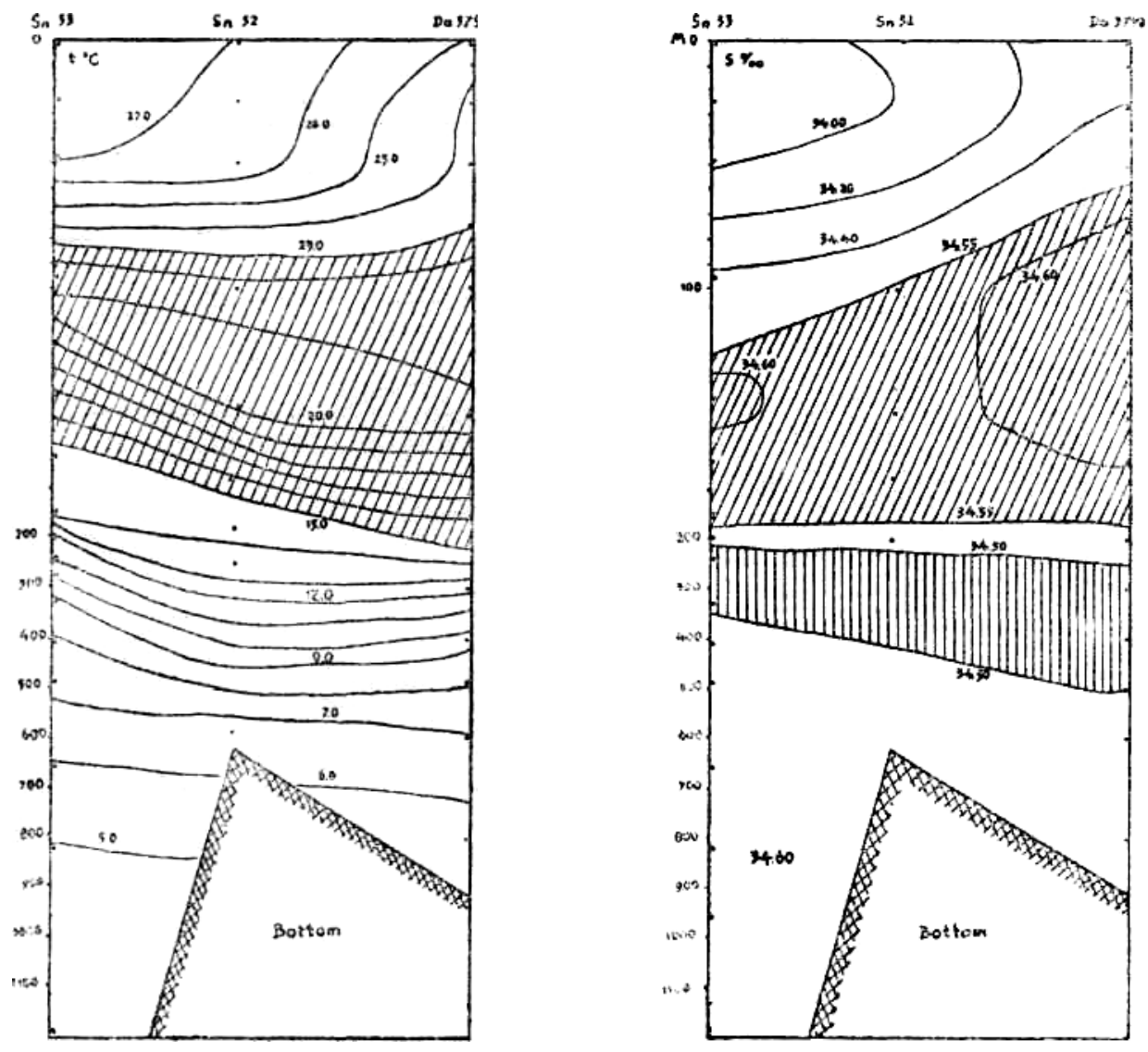

Figure 6. The cross section of temperature and salinity off Makassar coast along the line MM' in Figure 1, during the southeast monsoon. 
Subtropical Lower Water is found. It is indicated by the salinity maximum the thickness of which apparently also fluctuates seasonally between 130 to $200 \mathrm{~m}$ and 80 to $200 \mathrm{~m}$ respectively. Its core layer is bounded by the 15 $23^{\circ} \mathrm{C}$ isotherms and the $34.55 \%$ isohalines. Below the Subtropical Lower Water lies the Intermediate Water follows by the Deep Water. The presence of the Intermediate Water is indicated by the salinity minimum found below $200 \mathrm{~m}$. According to Wyrtki (1961) the extension of the Intermediate Water in this area is from $12^{\circ} \mathrm{C}$ to $9^{\circ} \mathrm{C}$ isotherms or between about 300 to 500 $\mathrm{m}$ while the Deep Water is present from $500 \mathrm{~m}$ down to the bottom. Both are clearly shown by Figure 5 and Figure 6.

The discontinuity layer in this area is found between 50 to $300 \mathrm{~m}$ as shown by Figure 7. From this figure it can be concluded that the Subtropical Lower Water occupies the upper half of the discontinuity layer. In accordance with what has been pointed out by Postma (1958) and Wyrtki (1961) it is clear from Figure 5, 6 and 7 that not only the Homogeneous Surface Layer but also the Subtropical Lower Water takes part in the seasonal circulation. It can be said therefore that during the northwest monsoon both water masses flow from the Southern Makassar Strait into the Flores Sea, the main flow being in southeasterly direction. No upwelling occurs during this season. However during the southeast monsoon the flow is more or less reversed, the main currents being actually in westerly direction (see Figure 4). During this season the upwelling occurs. The effect of the upward motion can especially be seen in the thickening of the layer of the Subtropical Lower Water in the south stations of Figure 6.

As will be pointed out later the time of upwelling is from June to September, a period of about four months. With the thermocline rise of 50 $\mathrm{m}$, this will give an average vertical velocity of the upwelled water of $5 \times 10$ ${ }^{4} \mathrm{~cm} / \mathrm{sec}$. This value is about the same as were found in the Banda Sea (Wyrtki, 1958) and South of Java (Wyrtki, 1962). The area of upwelling proper can be taken to be not more than four degrees square or about $48.000 \mathrm{sq} . \mathrm{km}$ (see Figure 2). Thus the contribution of the upwelling to the surface currents amounts to 0.2 million $\mathrm{m}^{3} / \mathrm{sec}$. that is only about $7 \%$ of the 3 million $\mathrm{m}^{3} / \mathrm{sec}$. transported in the west-going currents as given by Wyrtki (1961). Therefore it can be concluded that the upwelling in the Southern Makassar Strait only slightly effects the water circulation in the area and does not contribute significant amount of water masses to the west-going currents.

\section{DISCUSSION}

The evidence of upwelling in the Southern Makassar Strait can above all be seen in the salinity and temperature distribution at the surface layer. In earlier works this evidence did not show up clearly 


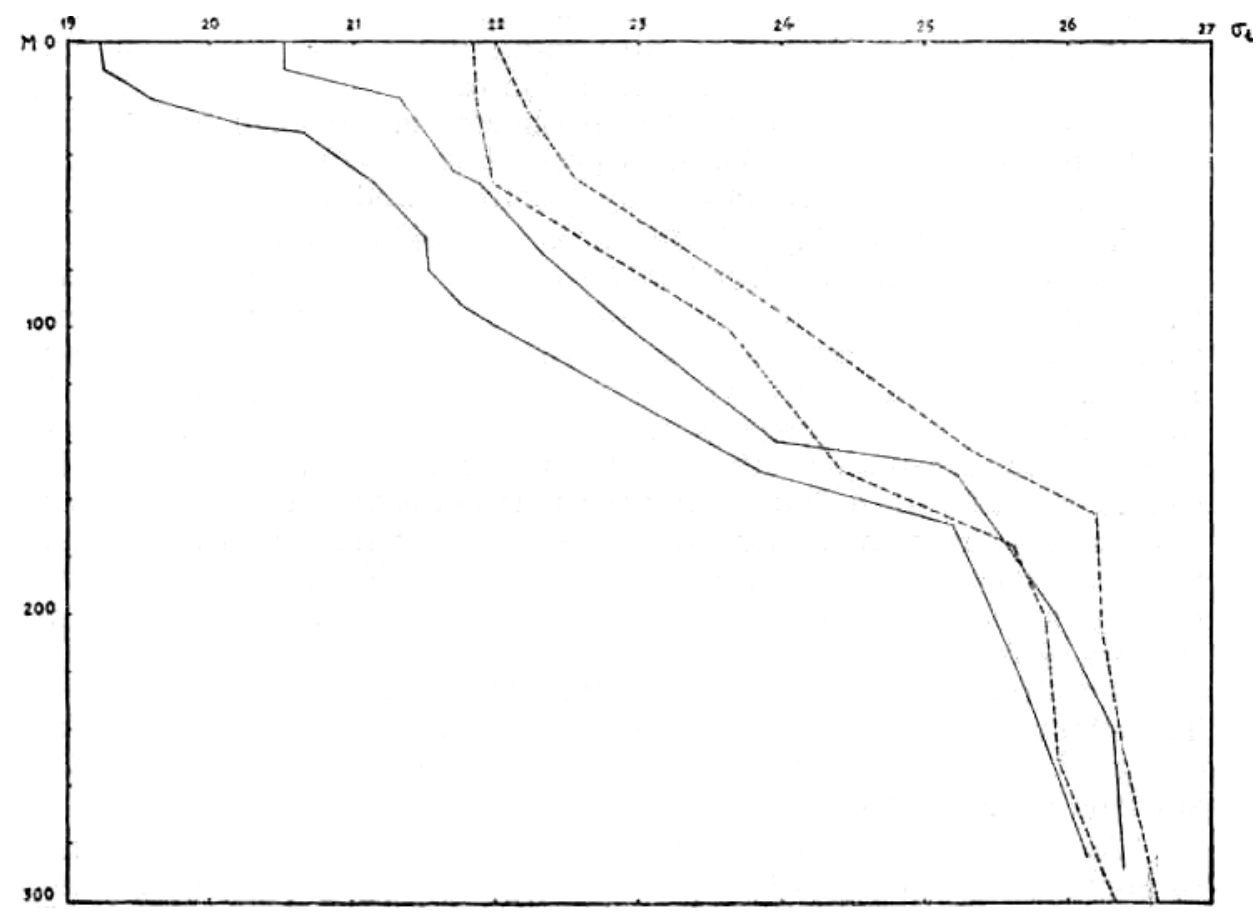

Figure 7. The envelopes of density (sigma-T) values in the Southern Makassar Strait. Solid lines represent the condition during the northwest monsoon and the dashed lines represent that during the southeast monsoon. 
due to the lack of data. With fairly large number of observations available at the L.P.L.'s file, it is possible now to draw charts of the surface salinity and temperature that can show the influence of upwelling. It is shown in the charts 1 to 12 for salinity and charts 13 to 24 for temperature. These charts are based on the normal monthly values tabulated in Table 1 and 2.

From the reports of Veen (1953), Hardenberg \& Soeriaatmadja (1955), Soeriaatmadja (1956), Sjarif (1959), Ilahude (1960), Wyrtki (1955, 1961) and others it can be concluded that the surface salinity distribution in the Southern Makassar Strait is mainly determined by two factors. Firstly the transportation of much diluted water from the Java Sea by the northwest monsoon currents and the transportation of high salinity water mass from the Flores Sea by the southeast monsoon currents. Secondly the rainfall during the northwest monsoon and the dry season during the southeast monsoon that give additional effect on decreasing and increasing the salinity.

The upwelling also can now be added as the third factor that determine both the salinity and the temperature distributions. Thus on the charts 1 to 12 it can be seen that from December to March of the northwest monsoon the salinity decreases continuously. In April and May, the latest phase of the transition period, the rain and the currents slacken to a stand still. It is seen that the salinity in these months starts to increase slightly due partly to the evaporation. In June the southeast monsoon starts and with it the transportation of the Flores Sea water mass into the area. Its effect is to increase the salinity further in June and July. Besides that pockets of area of still higher salinity, are found off the coast of Makassar. These high salinity areas can properly be explained by upwelling because in three other areas outside but adjacent to the Southern Makassar Strait the salinity is still low (see Figure 8). This condition goes on until September in which all the area of the Strait is covered by the water of homogeneous salinity higher than $34.00 \%$ o . A pocket of high salinity greater than $34.45 \%$ can still be seen off the coast of Makassar. The month of September usually marks the end of the southeast monsoon and therefore it can also be considered as the end of upwelling. October and November are the months of the second transition period. The salinity decreases slightly indicating the withdrawal of the Flores Sea water and the advancement of the Java Sea water. With the full northwest monsoon the salinity decreases further to its minimum in March.

Compared to the salinity, the surface temperature distribution does not show a well defined picture. The isotherms are not so regular as the isohalines. The reason might be due to the fact that the diurnal variation of temperature is much higher than the horizontal differences. Observations of L.P.L. in Lantjang Island (Java Sea) for example show that the diurnal variation can be $2{ }^{\circ} \mathrm{C}$ larger than the horizontal variation (unpublished data). Conse- 

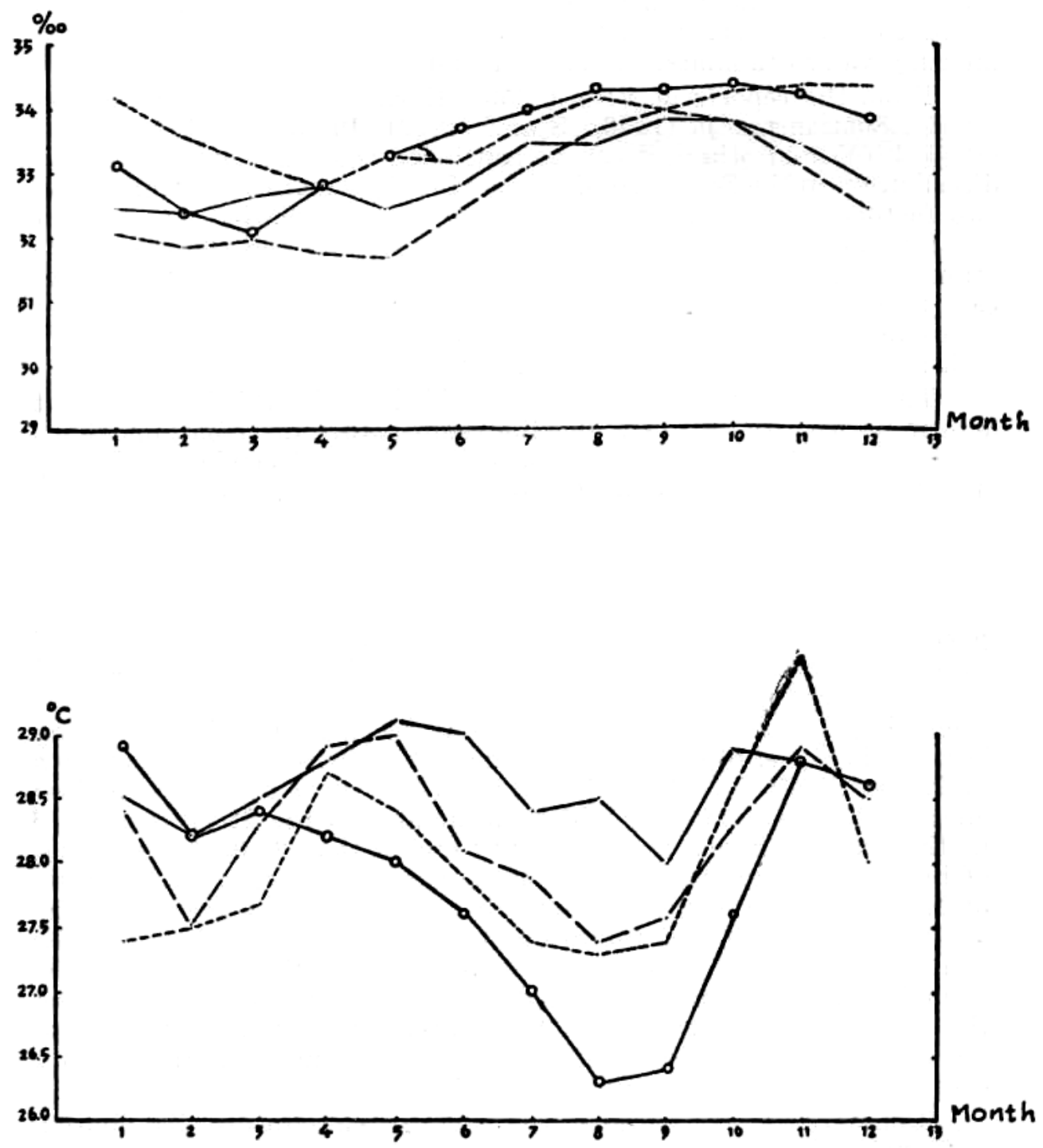

Figure 8 . The monthly surface salinity and temperature graphs in the area of upwelling ( o Makassar Strait o ) compared to those in the Northern Sea (--------). 
quently temperature observations made at different time of the day may complicate the picture of the horizontal distribution of temperature. This is the case with L.P.L.'s data on which the present charts of temperature are based. Nevertheless from these charts it is still possible to detect the seasonal or monthly variation of the surface temperature in this area. Also the effect of upwelling on its distribution is quite clear. Thus from December to February the average temperature decreases from $28.4-$ $29.0^{\circ} \mathrm{C}$ to $27.8-28.4^{\circ} \mathrm{C}$. The decrease can be explained as the results of the cooling effect of the rain and wind. In March the area is covered with a water of homogeneous temperature of $28.2-28.6^{\circ} \mathrm{C}$ which is slightly higher than in February. The temperature increases further in April and May to 28.2 $-29.2^{\circ} \mathrm{C}$, particularly in the west and northwest part of the area. The increase in temperature during the transition period of March, April and May is partly due to the calm condition that facilitates the heating process on the stagnant water and partly may be due to the influence of warm air mass above. But at present there is still not enough data to support the latter supposition.

Starting in June, when upwelling is already in the progress the temperature decreases steadily until September in which the temperature is $26.4-27.8^{\circ} \mathrm{C}$. It is to be noted that the temperature in the upwelling region during July, August, September is consistently lower than in the remainder of the area. In October the temperature starts to increase again to reach its maximum in November with values of $28.4-29.2{ }^{\circ} \mathrm{C}$. With the initiation of the northwest monsoon in December the temperature starts to decrease again to its minimum in February.

To get a clearer picture of the effect of upwelling on the surface salinity and temperature Figure 8 and 9 were drawn. Figure 8 is based on the normal values in Table 1 and 2. Each curve represents the condition in the Northern Makassar Strait (Square No. 0118), Java Sea (Square No. 0613), Flores Sea (Square No. 0723), all of them adjacent to the Southern Makassar Strait and the condition in the region of the upwelling itself (Square No. 0619). It should be added that the curve for Square No. 0619 is very similar to those for Square No. 0518 and CS19, both in the upwelling region (see Figure 2) and therefore is typical for the region. On Figure 8 it is seen that in June the salinity in the Southern Makassar Strait is already higher than in the other three areas because of the upwelling. This condition goes on until September, after which the salinity, greater than $34.007_{00}$ remains higher than the other until its maximum in October. With the initiation of the northwest monsoon in December the salinity decreases continuously to its minimum in March. Thus because of the different water masses that alternately occupy the area the surface salinity shows annual variation with a maximum in October and a minimum in March. One important 

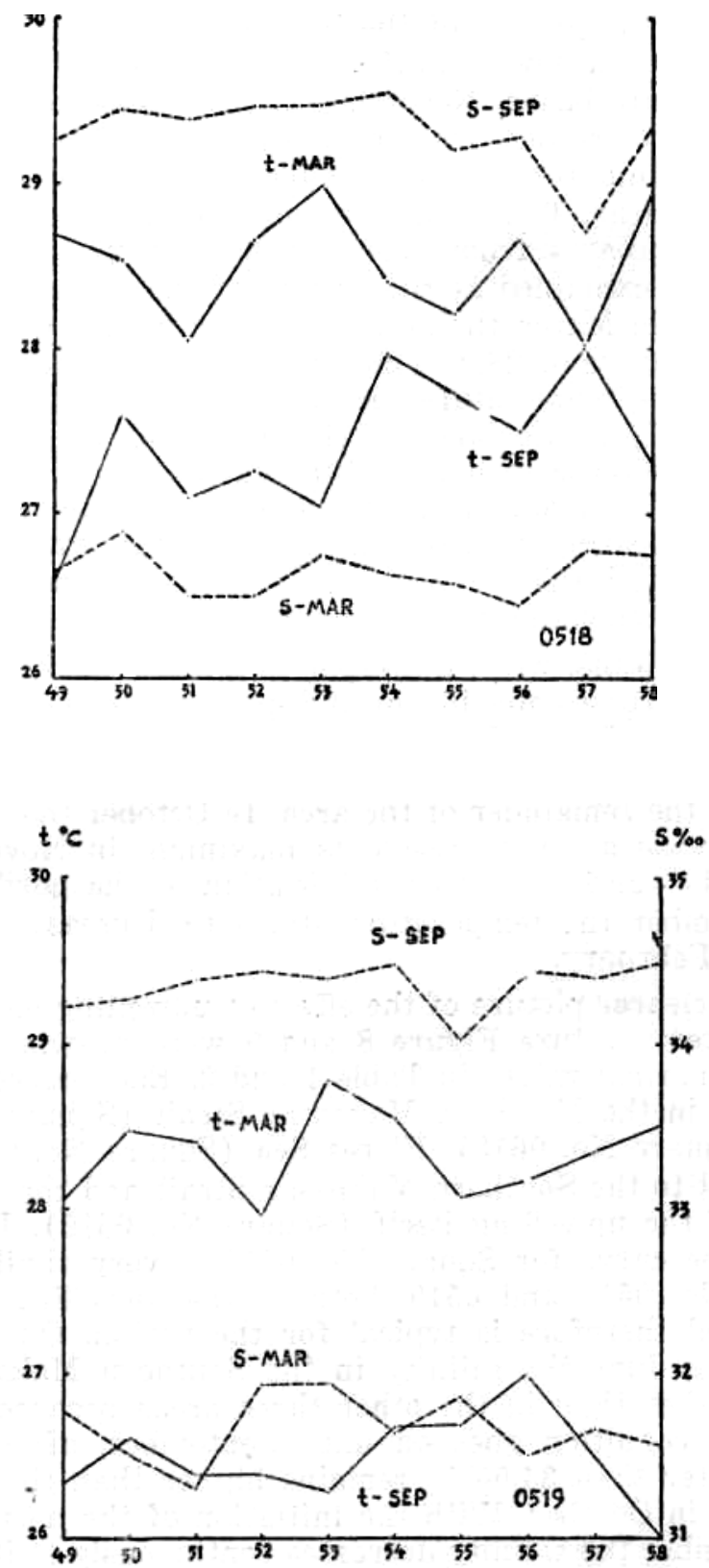

Figure 9. The yearly surface salinity and temperature graphs in the months March and September of the degree squares No. 0518 and 0510 in the area of upwelling 
feature is also seen, namely the longer period for the maximum (about 3 months) than the minimum (only 1 month) which is again due at least partly to the upwelling.

Regarding the temperature, Figure 8 shows that there are two minima and two maxima in the annual surface distribution of all the areas presented. The months in which the minima and maxima occur may be different for different areas. For the upwelling region the minima occur in February and August while the maxima occur in March and November a fact that has been shown by the charts. The feature that necessarily to be noted is that because of the upwelling the minimum temperature of the upwelling region is very much lower than the other three areas.

Figure 9 shows the monthly average temperature and salinity for March and September of the upwelling region in the year 1949 to 1958 (Table 4). It is seen that the temperature in September is consistently lower than in March while the reverse is true regarding the salinity. This fact suggests that the upwelling apparently occurs regularly each your though its intensity might varies according to the different intensity of the monsoons that cause it.

Besides the salinity and temperature distribution, the evidence of upwelling seems to be also shown by the surface distribution of the inorganic phosphate. Figure 10 shows the phosphate distribution obtained during the Jalanidhi cruise of March 1965 in the region. It can be seen that the phosphate in the upwelling region is quite high, amounting to more than $0.80 \mu \mathrm{g}$-at $\mathrm{P}-\mathrm{PO}_{4} / \mathrm{L}$. It should be stressed here that this distribution is for the months February - March, in which there is no occurrence of upwelling. Furthermore the phosphate values shown in the Figure 10 are certainly too high. This fact is demonstrated by Figure 11. This Figure shows the results of several phosphate determinations in the Banda Sea, in comparison with the present result in the Southern Makassar Strait. The Banda Sea is represented by three curves of vertical phosphate distribution, each is respectively based on the data of Snellius redrawn from Postma (1958), the data of Diamantina (C. S. I. R, 0. S. Oceanographical Cruise Report No. 14, station no. 26), and the data of Jalanidhi (Ilahude, 1970 station no. 16). The Makassar Strait is represented by one curve based on the Jalanidhi cruise in the region (Ilahude, unpublished manuscript). It is seen form this Figure that while the phosphate value for the Banda Sea more or less are in agreement with each other, that of the Makassar Strait is in the average 0.50 (jig-at/L higher than the former. Though the reason is yet unknown, it is clear that the Makassar Strait data are in error and should be corrected by this amount. If this is done then the values of Figure 10 will come down to within the limits of 0.10 to $0.30 \mathrm{j} / \mathrm{g}$-at $/ \mathrm{L}$ for the most part of the area. These limits are about the same as for the Banda sea, another area of upwelling, as shown in Figure 12. 


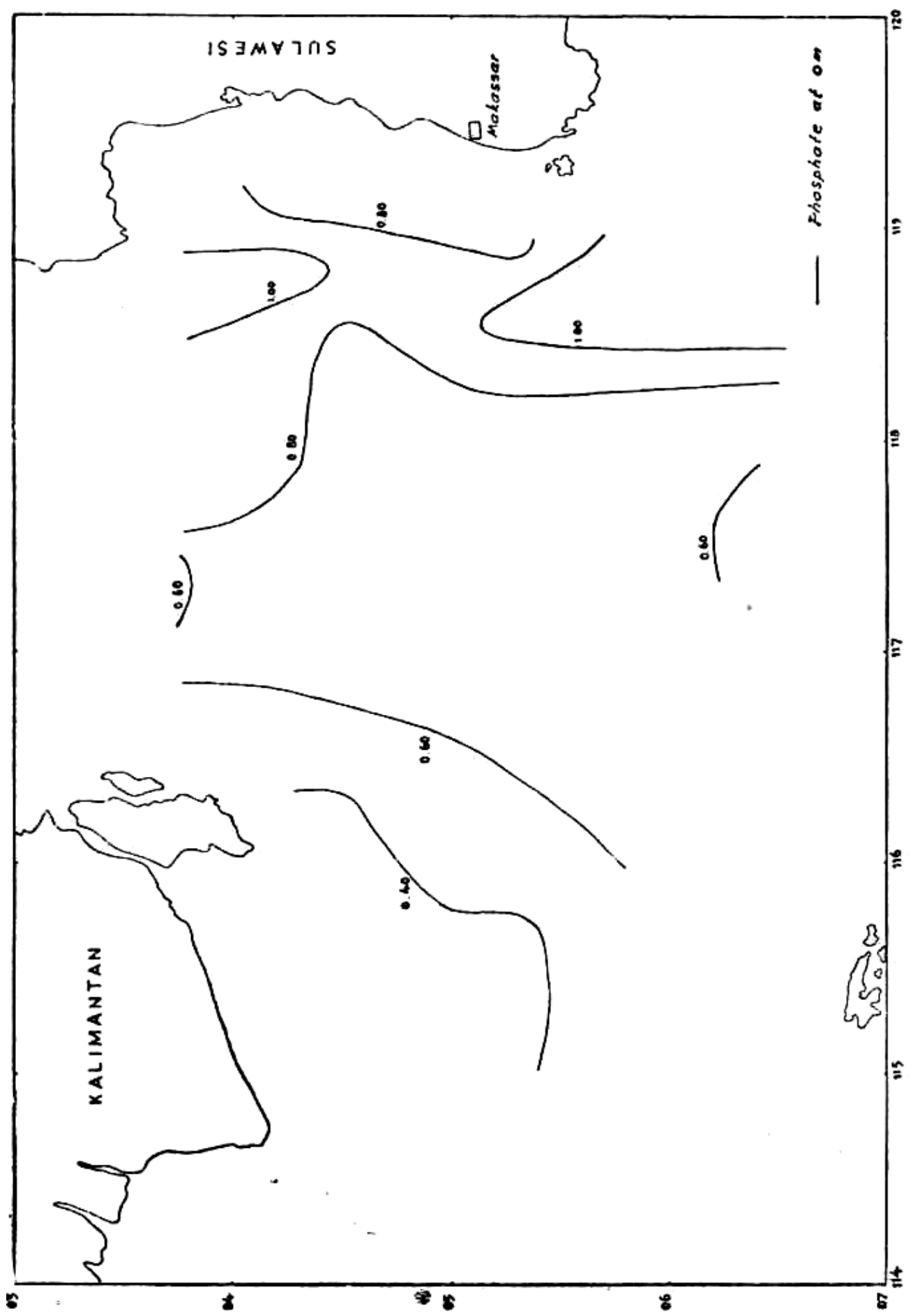

Figure 10. The surface phosphate distribution in the southern Makassar Strait during the Jalanidhi cruise of March-1965. 


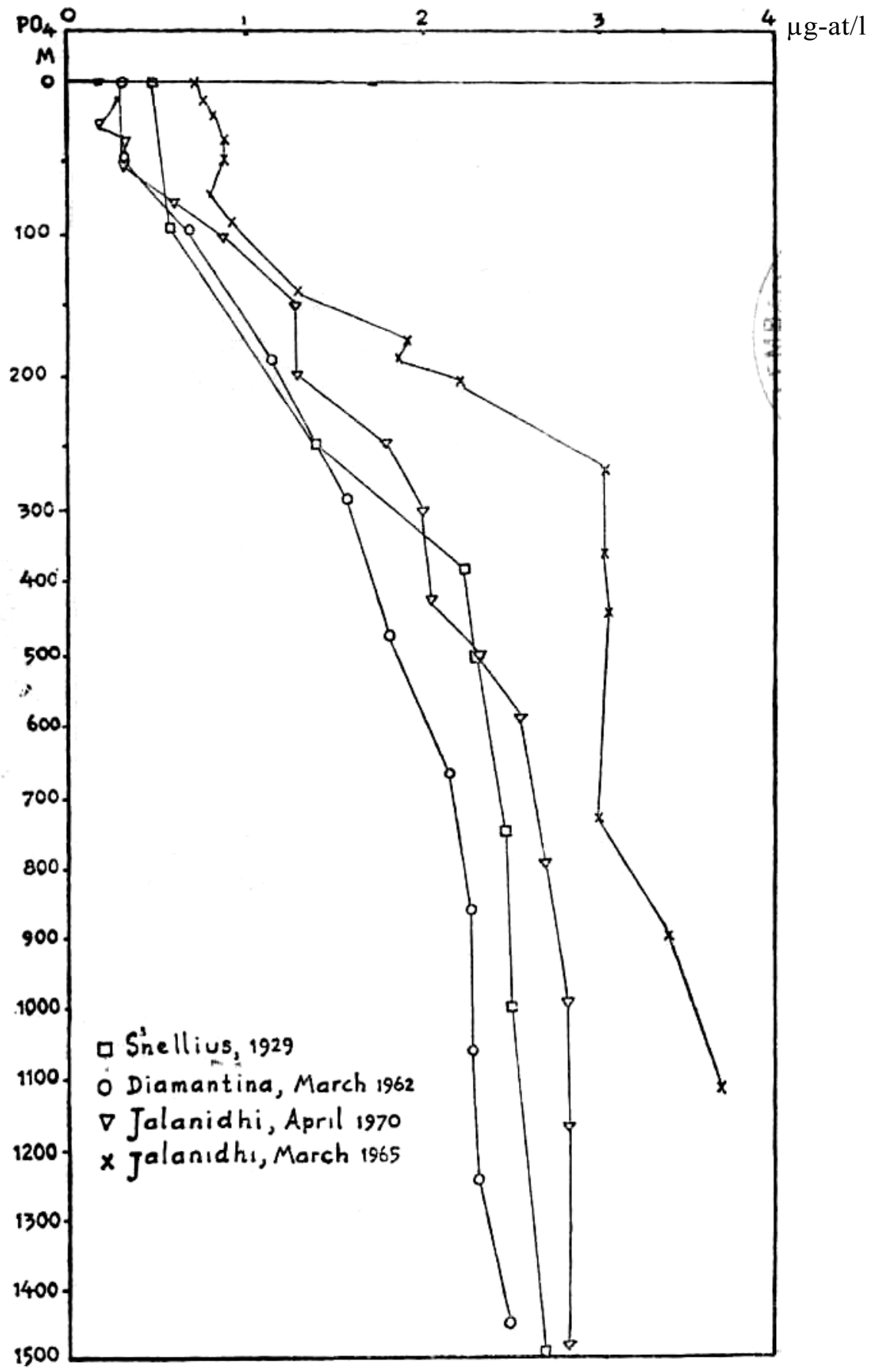

Figure 11. The vertical distribution of inorganic phosphate in the Banda Sea $<\square, 0, \Delta$ ) Compared to that in the Southern Makassar Strait (x). 


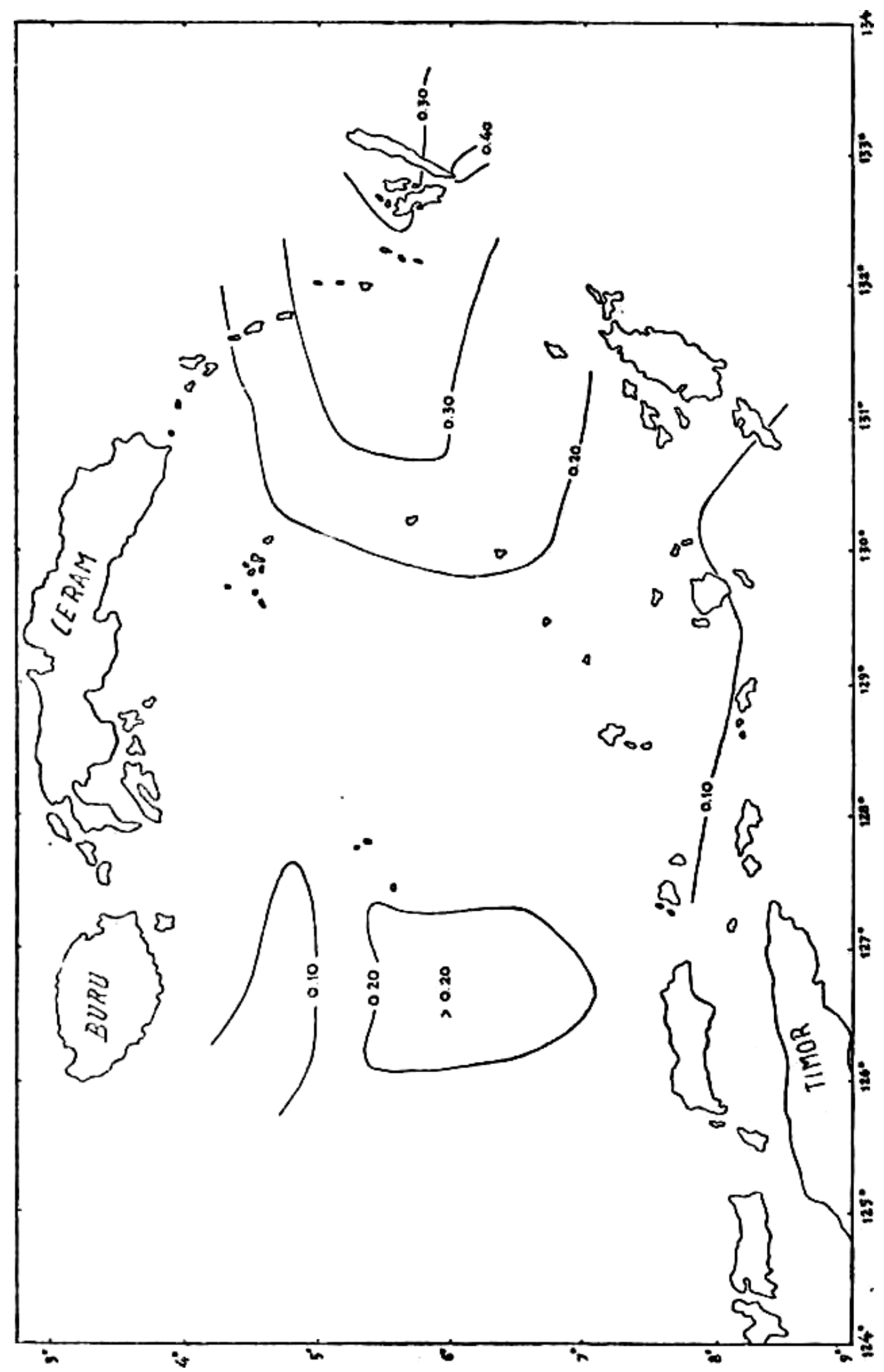

Figure 12. The surface phosphate distribution in the Banda Sea, after Ilahude (1970) 
figure 12 is taken from Ilahude (1970) and shows the surface phosphate distribution during the same season, namely just before upwelling (April 1970). Both Figure 10 and 12 show that in general the phosphate increases from west to east and at what may be regarded as the center of upwelling the phosphate value is particularly high.

Further examination of phosphate data of the other Indonesian Seas where no upwelling occurs, reveals that the phosphate in these areas varies slightly from season to season. For example in the Java Sea Delsman (1940) found that the average surface content of phosphate varies between $4.7 \mathrm{mg}$ $\mathrm{P}-\mathrm{P}_{2} \mathrm{O}_{5} / \mathrm{m}^{3}$ in April and $5.5 \mathrm{mg} \mathrm{P}-\mathrm{PoO}_{5} / \mathrm{m}^{3}$ in October. These values are equivalent to 0.07 and $0.08 \mu \mathrm{g}$-at $\mathrm{P}_{-} \mathrm{PO}_{4} /$ respectively, and are much too low compared to those tabulated in Table 3. The high values for L.P.L.'s data may be at least partly due to the fact that all their extinction readings were not corrected for turbidity factor. However these data also indicate that the average phosphate in Java Sea varies slightly from season to season, namely between $0.21 \mu \mathrm{g}$-at $/ \mathrm{L}$ in March and $0.24 \mu \mathrm{g}$-at $/ \mathrm{L}$ in September. In the Bali Strait it varies between $0.22 \mu \mathrm{g}$-at $/ \mathrm{L}$ in March and $0.35 \mu \mathrm{g}$-at $/ \mathrm{L}$ in October. It is seen that the largest seasonal difference of the average values of these two areas is only $0.13 \mu \mathrm{g}$-at/L. Compared to this the seasonal difference in the Indian Ocean, south of Java, is relatively high. The average phosphate values in this area are $0.24 \mu \mathrm{g}-\mathrm{at} / \mathrm{L}$ in April and $0.58 \mu \mathrm{g}-\mathrm{at} / \mathrm{L}$ in October. The difference is 0.34 or more than twice that of the Java Sea and Bali Strait. The individual values of some of the stations south of Java are even higher than $0.80 \mu \mathrm{g}$-at/L in October (Table 3 ). The reason for the high seasonal difference south of Java is of course the presence of upwelling in this area during the southeast monsoon as reported by Wyrtki (1962).

The slight seasonal differences of phosphate in the areas with no upwelling may suggest the same rate of phosphate rejuvination and consumption seasonally at the surface layer of these waters. However in the areas of upwelling the amount of consumption may at times not fully balance the rejuvination because of the upwelling. If this is also the case with the Southern Makassar Strait, then the presence of high phosphate in the region off the coast of Makassar during the northwest monsoon, as well as in the Banda Sea, can be explained by the large supply due to the upwelling during the previous southeast monsoon.

\section{CONCLUDINGREMARKS}

From the foregoing it can be concluded with fair certainty that upwelling does occur off the coast of Makassar. It occurs only during the southeast monsoon and therefore according to the classification of Wyrtki (1961) it belongs to the periodic type. Based on the 
area of upwelling and the estimated vertical velocity it has been shown that the upwelling only slightly contributes to the surface circulation of the Southern Makassar Strait.

However it does influence the hydrological features of the area. Its effect can be seen in the monthly distribution of surface salinity and temperature. It also seems to enrich the surface layer with inorganic phosphate.

It is interesting to know whether the same is also true for other nutrients and whether these nutrients are effectively used by the plankton. It is therefore desirable to have a more thorough observation in the area, especially in regard to productivity and standing crop measurement of phytoplankton accompanied by light, nitrate and silicate determination beside those that have been done.

\section{ACKNOWLEDGEMENT}

Sincerest thanks are extended to Dr. Gordon W. Groves and Dr. Klaus Wyrtki of the University of Hawaii for reading the manuscript and for the helpful comments. Great appreciation is also extended to Lieutenant Colonel Sjamsoeddin (IN) and the crews of R/V Jalanidhi for their good cooperation in executing the observations in the Makassar Strait. 
Delsman, H.C. 1940.

\section{REFERENCES}

Preliminary plankton investigations in the Java Sea.

C.S.I.R.O. 1964.

Treubia Vol. 17, p. $139-182$.

Oceanographical Cruise Report No. 14 Australia.

Hardenberg, J. D. F. and Rd. E. Soeriaatmadja, 1955.

Monthly mean salinities in the Indonesian Archipelago and adjacent

waters for the months: March 1950 - February 1953.

Org. Scie. Res. Bull. no. 21, 68 pp.

Ilahude, A. G. 1960.

The salinity and its distribution in the sea.

(unpublished B. Sc. thesis in Indonesian). $-1970$.

Report Of Oceanographic Work In The Banda Sea. (Unpublished report in Indonesian)

------------Oceanographic Station List 1963 - 1966 (Unpublished manuscript).

Postma, H. 1958.

The chemical results and a survey of water masses and currents.

The Snellius Expedition. Vol. II, part 8, 116 pp.

Sjarif, Sjarmilah, 1959.

Seasonal fluctuation in the surface salinity along the coast of the southern part of Kalimantan (Borneo).

Mar. Res. Indon. No. 4, p. 1 - 25.

Soeriaatmadja, Rd. E. 1956.

Seasonal fluctuations in the surface salinity off the north coast of Java. Mar. Res. Indon. No. 1, p. 1 - 20.

Thomsen, H. 1935.

Hydrographical observations made during the "Dana-Expedition" 1928-

30. Dana Report No. 12, 46 pp.

Van Riel, P. M., H. C. Hamaker and L. van Eyck. 1950.

Serial and bottom observations temperature, salinity and density.

The Snellius Expedition. Vol. II, part 6, 44 pp.

Veen, P. Ch. 1951.

Surface salinities in the Indonesian Archipelago and adjacent waters.

Org. Scie. Res. Publ. No. 33, 20 pp.

- 1953.

Preliminary charts of the mean salinity of the Indonesian Archipelago and adjacent waters. Org. Scie. Res. Bull. no. 17, 47 pp.

Wyrtki, 1955.

Monthly charts of surface salinity in Indonesian and adjacent waters. J. du

Conseil, Perm. Int. Explo de la Mer. Vol. 21, No. 1, pp. 268 - 279.

1957.

Die Zirkulation an der Oberflache der Sudostasiatischen Gewasser. Deut. Hydr. Zeit., Jrg. 10 Heft 1, Sn 1 - 18.

--1958.

The water exchange between the Pacific and the Indian Oceans in relation to upwelling processes. Proc. 9th. Pac. Scie. Congr., Vol. 16, p 61-71. $-1961$.

Physical oceanography of the Southeast Asian Waters. Naga Report Vol.

2, Scripps. Inst. Ocean., California.

-1962;

The upwelling in the region between Java and Australia during the southeast monsoon.

Austr. Journ. Mar. Freshw. Res. Vol. 13, no. 3, p, 217 - 225. 
TABLE 1. THE "NORMAL" MONTHLY SALINITY IN THE SOUTHERN SQUARE ACCORDING TO THE

\begin{tabular}{|c|c|c|c|c|c|c|c|c|c|c|c|c|}
\hline \multirow{2}{*}{$\begin{array}{c}\text { Degree } \\
\text { Square No. }\end{array}$} & \multicolumn{2}{|c|}{ Jan. } & \multicolumn{2}{|c|}{ Feb. } & \multicolumn{2}{|c|}{ Mar. } & \multicolumn{2}{|c|}{ Apr. } & \multicolumn{2}{|c|}{ May } & \multicolumn{2}{|c|}{ Jun. } \\
\hline & $\mathbf{s}$ & No. & $\mathbf{S}$ & No. & $\mathbf{S}$ & No. & $\mathbf{S}$ & No. & $\mathbf{S}$ & No. & $\mathbf{S}$ & No. \\
\hline 0316 & 30.8 & 96 & 30.1 & 65 & 30.2 & 75 & 30.8 & 89 & 31.2 & 87 & 32.2 & 95 \\
\hline 0317 & - & - & 30.2 & 1 & 30.5 & 8 & 30.8 & 5 & 31.4 & 8 & 32.0 & 5 \\
\hline 0318 & 32.1 & 90 & 31.6 & 93 & 31.8 & 66 & 32.4 & 37 & 32.8 & 126 & 33.1 & 113 \\
\hline 0319 & 31.7 & 9 & 30.9 & 6 & 31.5 & 16 & 32.3 & 12 & 32.8 & 8 & 33.6 & 10 \\
\hline 0415 & 30.6 & 59 & 29.7 & 36 & 30.0 & 47 & 30.4 & 51 & 31.3 & 53 & 32.4 & 51 \\
\hline 0416 & 30.5 & 88 & 29.6 & 76 & 29.7 & 89 & 30.4 & 69 & 31.1 & 81 & 32.8 & 89 \\
\hline 0417 & 31.9 & 4 & 31.3 & 11 & - & - & 31.0 & 10 & 31.8 & 9 & 33.0 & 9 \\
\hline 0418 & 32.2 & 119 & 31.4 & 94 & 31.3 & 133 & 31.9 & 35 & 32.7 & 141 & 33.4 & 115 \\
\hline 0419 & 31.5 & 28 & 31.3 & 13 & 31.1 & 24 & 31.8 & 14 & 33.3 & 8 & 33.6 & 13 \\
\hline 0516 & 32.0 & 49 & 31.8 & 48 & 31.3 & 88 & 31.2 & 65 & 32.2 & 92 & 33.0 & 71 \\
\hline 0517 & 32.2 & 82 & 32.0 & 89 & 31.5 & 108 & 31.8 & 82 & 32.7 & 124 & 33.1 & 89 \\
\hline 0518 & 32.5 & 164 & 31.8 & 108 & 31.7 & 210 & 32.3 & 170 & 32.9 & 220 & 33.5 & 200 \\
\hline 0519 & 32.3 & 191 & 31.8 & 191 & 31.6 & 201 & 32.5 & 172 & 33.3 & 185 & 33.7 & 158 \\
\hline 0615 & 32.0 & 37 & 31.9 & 33 & 31.7 & 41 & 31.4 & 41 & 32.1 & 38 & 33.1 & 41 \\
\hline 0616 & 32.4 & 66 & 32.0 & 65 & 31.6 & 69 & 31.5 & 64 & 32.6 & 78 & 33.3 & 75 \\
\hline 0617 & 32.3 & 75 & 32.0 & 50 & 31.7 & 64 & 32.0 & 72 & 32.8 & 82 & 33.3 & 77 \\
\hline 0618 & 32.6 & 49 & 32.1 & 34 & 31.9 & 39 & 32.3 & 42 & 33.1 & 47 & 33.6 & 35 \\
\hline 0619 & 33.1 & 46 & 32.4 & 44 & 32.1 & 48 & 32.8 & 66 & 33.3 & 59 & 33.7 & 49 \\
\hline 0118 & 32.5 & 23 & 32.4 & 21 & 32.7 & 20 & 32.8 & 17 & 32.5 & 34 & 32.8 & 30 \\
\hline 0613 & 32.1 & 130 & 31.9 & 111 & 32.0 & 156 & 31.8 & 152 & 31.7 & 63 & 32.4 & 184 \\
\hline 0723 & 34.2 & 3 & 33.6 & 5 & 33.2 & 6 & 32.8 & 9 & 33.3 & 6 & 33.2 & 2 \\
\hline
\end{tabular}


MAKASSAR STRAIT AND ADJACENT AREAS FOR EACH DEGREE FILE OF L. P. L.

\begin{tabular}{|c|c|c|c|c|c|c|c|c|c|c|c|c|}
\hline \multicolumn{2}{|c|}{ Jul. } & \multicolumn{2}{|c|}{ Aug. } & \multicolumn{2}{|c|}{ Sep. } & \multicolumn{2}{|c|}{ Oet. } & \multicolumn{2}{|c|}{ Nov. } & \multicolumn{2}{|c|}{ Dec. } & \multirow{2}{*}{ Total } \\
\hline $\mathbf{s}$ & No. & $\mathbf{s}$ & No. & $\mathbf{s}$ & No. & $\mathbf{s}$ & No. & $\mathbf{S}$ & No. & $\mathbf{s}$ & No. & \\
\hline 83.2 & 102 & 33.4 & 114 & 33.8 & 112 & 38.6 & 100 & 32.9 & 97 & 32.1 & 99 & 1131 \\
\hline 33.3 & 3 & 34.0 & 8 & 34.6 & 4 & 33.9 & 11 & 33.6 & 8 & 33.4 & 8 & 64 \\
\hline 33.7 & 121 & 34.0 & 127 & 31.2 & 110 & 34.1 & 120 & 33.8 & 123 & 33.0 & 126 & 1252 \\
\hline 34.4 & 10 & 34.3 & 4 & 34.2 & 11 & 34.2 & 13 & 33.6 & 9 & 33.3 & 9 & 117 \\
\hline 33.4 & 47 & 33.9 & 56 & 34.1 & 63 & 34.2 & 64 & 32.9 & 51 & 32.5 & 59 & 687 \\
\hline 33.4 & 89 & 38.7 & 101 & 33.8 & 87 & 33.9 & 109 & 33.3 & 93 & 31.6 & 103 & 1074 \\
\hline 33.1 & 10 & 34.0 & 3 & 33.6 & 13 & 34.0 & 5 & 34.0 & 10 & 32.3 & 7 & 91 \\
\hline 33.9 & 111 & 34.2 & 110 & 34.3 & 121 & 34.0 & 113 & 33.8 & 119 & 33.2 & 120 & 1331 \\
\hline 34.1 & 16 & 34.3 & 1 & 34.4 & 33 & 34.2 & 17 & 33.8 & 37 & 32.9 & 47 & 251 \\
\hline 33.7 & 56 & 33.9 & 65 & 34.3 & 56 & 34.1 & 63 & 33.5 & 42 & 32.5 & 55 & 750 \\
\hline 33.9 & 77 & 34.1 & 109 & 34.2 & 89 & 34.2 & 95 & 33.9 & 75 & 33.3 & 100 & 1119 \\
\hline 34.0 & 50 & 34.1 & 211 & 34.3 & 171 & 34.1 & 188 & 34.0 & 172 & 33.3 & 183 & 2056 \\
\hline 34.0 & 51 & 34.1 & 211 & 34.3 & 180 & 34.3 & 222 & 34.0 & 194 & 33.4 & 184 & 2140 \\
\hline 33.5 & 42 & 34.0 & 64 & 34.2 & 42 & 34.1 & 46 & 39.7 & 34 & 32.6 & 41 & 500 \\
\hline 33.7 & 45 & 31.1 & 83 & 34,2 & 76 & 34.3 & 71 & 33.9 & 72 & 38.3 & 87 & 851 \\
\hline 33.9 & 57 & 34.0 & 87 & 34.3 & 70 & 34.2 & 91 & 34.2 & 80 & 33.4 & 78 & 883 \\
\hline 34.0 & 15 & 34.2 & 48 & 34.3 & 39 & 34.1 & 63 & 34.1 & 59 & 33.7 & 48 & 518 \\
\hline 34.0 & 13 & 34.3 & 53 & 34.2 & 48 & 34.4 & 55 & 34.3 & 52 & 33.9 & 49 & 582 \\
\hline 33.5 & 34 & 33.5 & 29 & 33.9 & 27 & 33.9 & 39 & 33.5 & 30 & 32.9 & 48 & 352 \\
\hline 33.1 & 36 & 33.7 & 226 & 34.0 & 175 & 33.9 & 176 & 33.2 & 122 & 32.5 & 137 & 1668 \\
\hline 33.8 & 9 & 34.2 & 5 & 34.0 & 6 & 34.3 & 4 & 34.4 & 3 & 34.4 & 3 & 61 \\
\hline
\end{tabular}


TABLE 2. THE "NORMAL" MONTHLY TEMPERATURE IN THE SOUTHERN SQUARE ACCORDING TO

\begin{tabular}{|c|c|c|c|c|c|c|c|c|c|c|c|c|}
\hline \multirow{2}{*}{$\begin{array}{c}\text { Degree } \\
\text { Square No. }\end{array}$} & \multicolumn{2}{|c|}{ Jan. } & \multicolumn{2}{|c|}{ Feb. } & \multicolumn{2}{|c|}{ Mar. } & \multicolumn{2}{|c|}{ Apr. } & \multicolumn{2}{|c|}{ Mei } & \multicolumn{2}{|c|}{ Jun. } \\
\hline & $t$ & No. & $t$ & No. & $t$ & No. & $t$ & No. & $t$ & No. & $t$ & No. \\
\hline 0316 & 27.9 & 75 & 28.2 & 44 & 28.2 & 62 & 28.9 & 68 & 29.0 & 55 & 28.7 & 72 \\
\hline 0317 & - & - & 27.8 & 2 & 28.5 & 8 & 29.1 & 5 & 29.2 & 7 & 28.9 & 5 \\
\hline 0318 & 28.2 & 67 & 28.1 & 76 & 28.8 & 60 & 28.6 & 35 & 28.9 & 111 & 28.4 & 90 \\
\hline 0319 & 28.2 & 9 & 27.5 & 3 & 28.4 & 9 & 29.3 & 10 & 29.1 & 8 & 28.1 & 10 \\
\hline 0415 & 28.6 & 57 & 27.8 & 33 & 28.7 & 47 & 29.3 & 48 & 29.0 & 48 & 28.6 & 50 \\
\hline 0416 & 28.0 & 73 & 28.1 & 55 & 28.3 & 71 & 29.3 & 57 & 28.9 & 59 & 28.4 & 74 \\
\hline 0417 & 28.4 & 3 & 28.5 & 11 & - & - & 29.3 & 10 & 29.3 & 10 & 28.2 & 9 \\
\hline 0418 & 27.7 & 97 & 28.0 & 64 & 28.4 & 101 & 28.8 & 34 & 28.9 & 115 & 28.4 & 98 \\
\hline 0419 & 28.2 & 15 & 28.1 & 11 & 28.3 & 18 & 28.6 & 13 & 28.9 & 7 & 28.4 & 10 \\
\hline 0516 & 28.7 & 45 & 28.0 & 39 & 28.8 & 83 & 29.0 & 62 & 28.5 & 81 & 28.0 & 61 \\
\hline 0517 & 28.1 & 78 & 27.9 & 83 & 28.3 & 99 & 28.8 & 94 & 28.5 & 114 & 27.9 & 87 \\
\hline 0518 & 28.2 & 141 & 28.0 & 93 & 28.4 & 189 & 28.8 & 165 & 28.5 & 198 & 28.0 & 184 \\
\hline 0519 & 28.2 & 163 & 28.1 & 181 & 28.4 & 157 & 28.4 & 155 & 28.2 & 174 & 27.8 & 141 \\
\hline 0615 & 28.2 & 37 & 27.8 & 34 & 28.6 & 37 & 29.3 & 40 & 29.0 & 36 & 28.1 & 39 \\
\hline 0616 & 28.1 & 62 & 28.5 & 60 & 28.5 & 67 & 28.9 & 65 & 28.6 & 75 & 27.8 & 71 \\
\hline 0617 & 28.5 & 73 & 27.9 & 47 & 28.5 & 58 & 28.8 & 69 & 28.5 & 84 & 28.1 & 77 \\
\hline 0618 & 28.1 & 29 & 28.1 & 18 & 28.2 & 14 & 28.7 & 24 & 28.4 & 30 & 27.8 & 22 \\
\hline 0619 & 28.9 & 24 & 28.2 & 25 & 28.4 & 28 & 28.2 & 47 & 28.0 & 40 & 27.6 & 32 \\
\hline 0118 & 28.5 & 24 & 28.2 & 20 & 28.5 & 20 & 28.8 & 18 & 29.1 & 27 & 29.0 & 30 \\
\hline 0613 & 28.4 & 102 & 27.5 & 17 & 28.3 & 106 & 28.9 & 152 & 29.0 & 163 & 28.1 & 180 \\
\hline 0723 & 27.4 & 3 & 27.5 & 5 & 27.7 & 7 & 28.7 & 8 & 28.4 & 6 & 27.9 & 2 \\
\hline
\end{tabular}


MAKASSAR STRAIT AND ADJACENT AREAS FOR EACH DEGREE THE FILE OF L. P. L.

\begin{tabular}{|c|c|c|c|c|c|c|c|c|c|c|c|c|}
\hline \multicolumn{2}{|c|}{ Jul. } & \multicolumn{2}{|c|}{ Aug. } & \multicolumn{2}{|c|}{ Sep. } & \multicolumn{2}{|c|}{ Oet. } & \multicolumn{2}{|c|}{ Nov. } & \multicolumn{2}{|c|}{ Dec. } & \multirow{2}{*}{ Total } \\
\hline $\mathbf{t}$ & No. & $t$ & No. & $t$ & No. & $t$ & No. & $t$ & No. & $t$ & No. & \\
\hline 27.8 & 81 & 27.9 & 91 & 27.8 & 91 & 27.8 & 87 & 28.5 & 84 & 28.5 & 81 & $=891$ \\
\hline 28.6 & 3 & 27.6 & 3 & 28.1 & 5 & 28.8 & 11 & 29.4 & 3 & 29.0 & 7 & 59 \\
\hline 27.8 & 96 & 27.8 & 108 & 28.0 & 90 & 28.3 & 102 & 28.8 & 71 & 28.6 & 111 & 1017 \\
\hline 27.3 & 10 & 28.1 & 4 & 28.0 & 10 & 29.2 & 14 & 29.4 & 8 & 28.5 & 7 & 102 \\
\hline 27.8 & 45 & 27.4 & 54 & 27.6 & 65 & 28.3 & 68 & 28.8 & 48 & 28.8 & 59 & 622 \\
\hline 27.7 & 74 & 27.5 & 88 & 27.5 & 72 & 28.3 & 90 & 28.3 & 71 & 28.6 & 77 & 861 \\
\hline 27.4 & 10 & 27.6 & 2 & 27.5 & 14 & 28.6 & 4 & 28.7 & 9 & 28.7 & 5 & 87 \\
\hline 27.7 & 92 & 27.4 & 89 & 27.7 & 102 & 28.2 & 99 & 28.7 & 84 & 28,4 & 96 & 1071 \\
\hline 27.6 & 15 & - & - & 27.2 & 34 & 27.9 & 16 & 28.5 & 38 & 28,4 & 44 & 221 \\
\hline 27.7 & 55 & 27.2 & 61 & 27.3 & 53 & 28.2 & 58 & 29.3 & 42 & 28.8 & 54 & 694 \\
\hline 27.3 & 75 & 27.1 & 105 & 27.3 & 87 & 28.1 & 91 & 28.6 & 81 & 28.6 & 96 & 1090 \\
\hline 27.2 & 42 & 27.3 & 180 & 27.3 & 146 & 27.9 & 178 & 28.8 & 141 & 28.3 & 160 & 1812 \\
\hline 26.9 & 43 & 26.7 & 183 & 26.4 & 153 & 27.7 & 193 & 28.7 & 152 & 28.4 & 163 & 1858 \\
\hline 27.8 & 42 & 27.6 & 60 & 27.5 & 41 & 28.3 & 44 & 28.6 & 34 & 28.5 & 39 & 483 \\
\hline 27.8 & 43 & 27.2 & 78 & 27.2 & 75 & 28.1 & 70 & 28.4 & 72 & 28.8 & 85 & 823 \\
\hline 27.2 & 41 & 27.0 & 78 & 27.3 & 64 & 27.8 & 91 & 28.8 & 78 & 28.8 & 74 & 834 \\
\hline 26.7 & 12 & 27.0 & 34 & 27.3 & 26 & 27.8 & 44 & 28.6 & 41 & 28.8 & 30 & 324 \\
\hline 27.0 & 12 & 26.3 & 35 & 26.5 & 37 & 27.6 & 40 & 28.8 & 35 & 28.6 & 28 & 383 \\
\hline 28.4 & 24 & 28.5 & 6 & 28.0 & 4 & 28.9 & 39 & 28.8 & 31 & 28.6 & 48 & 291 \\
\hline 27.9 & 31 & 27.4 & 219 & 27.6 & 177 & 28.3 & 164 & 28.9 & 114 & 28.5 & 139 & 1564 \\
\hline 27.4 & 9 & 27.3 & 4 & 27.4 & 7 & 28.6 & 4 & 29.6 & 3 & 28.0 & 3 & 61 \\
\hline & & & & & & & & & & & & 15148 \\
\hline
\end{tabular}




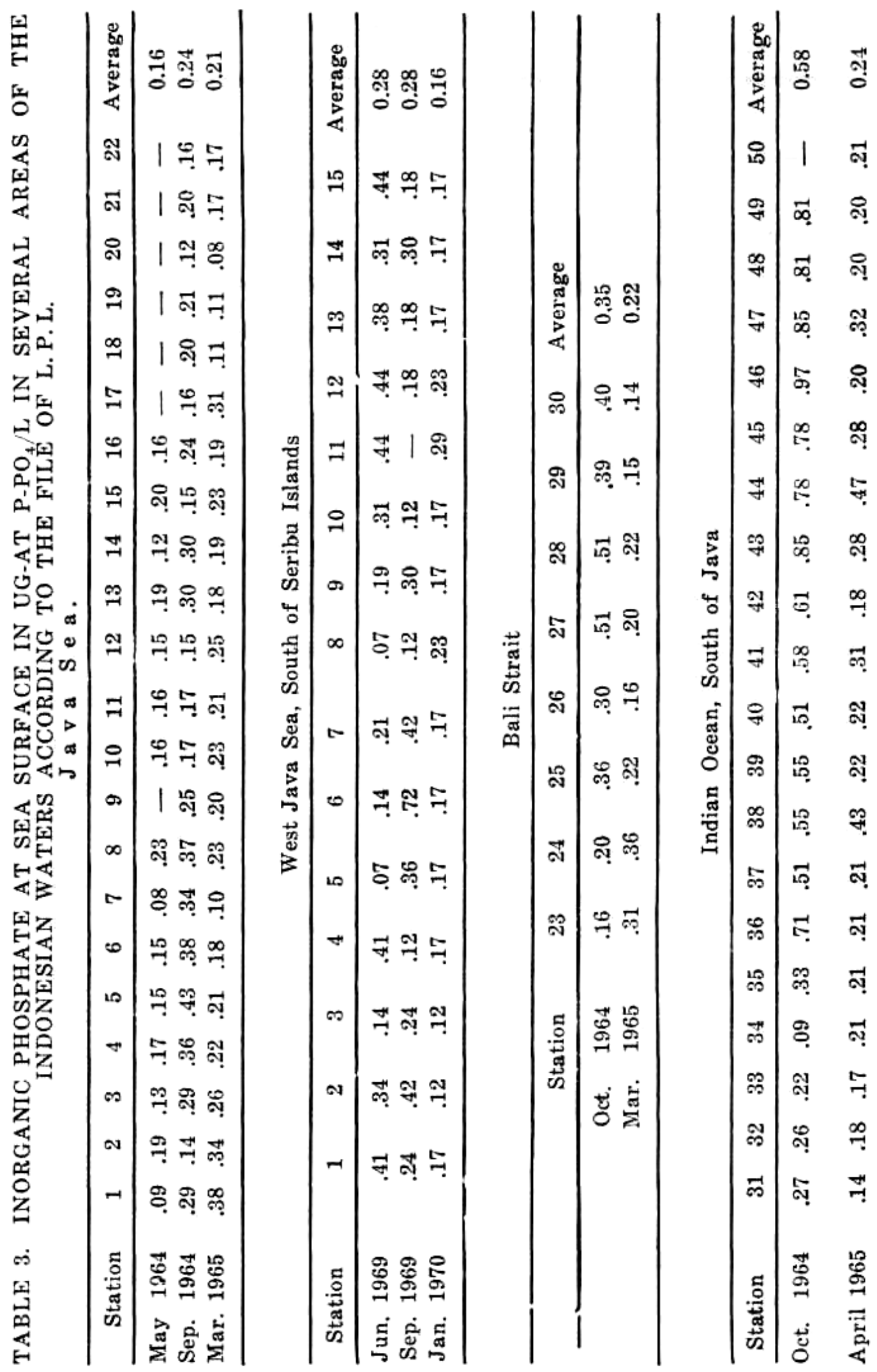









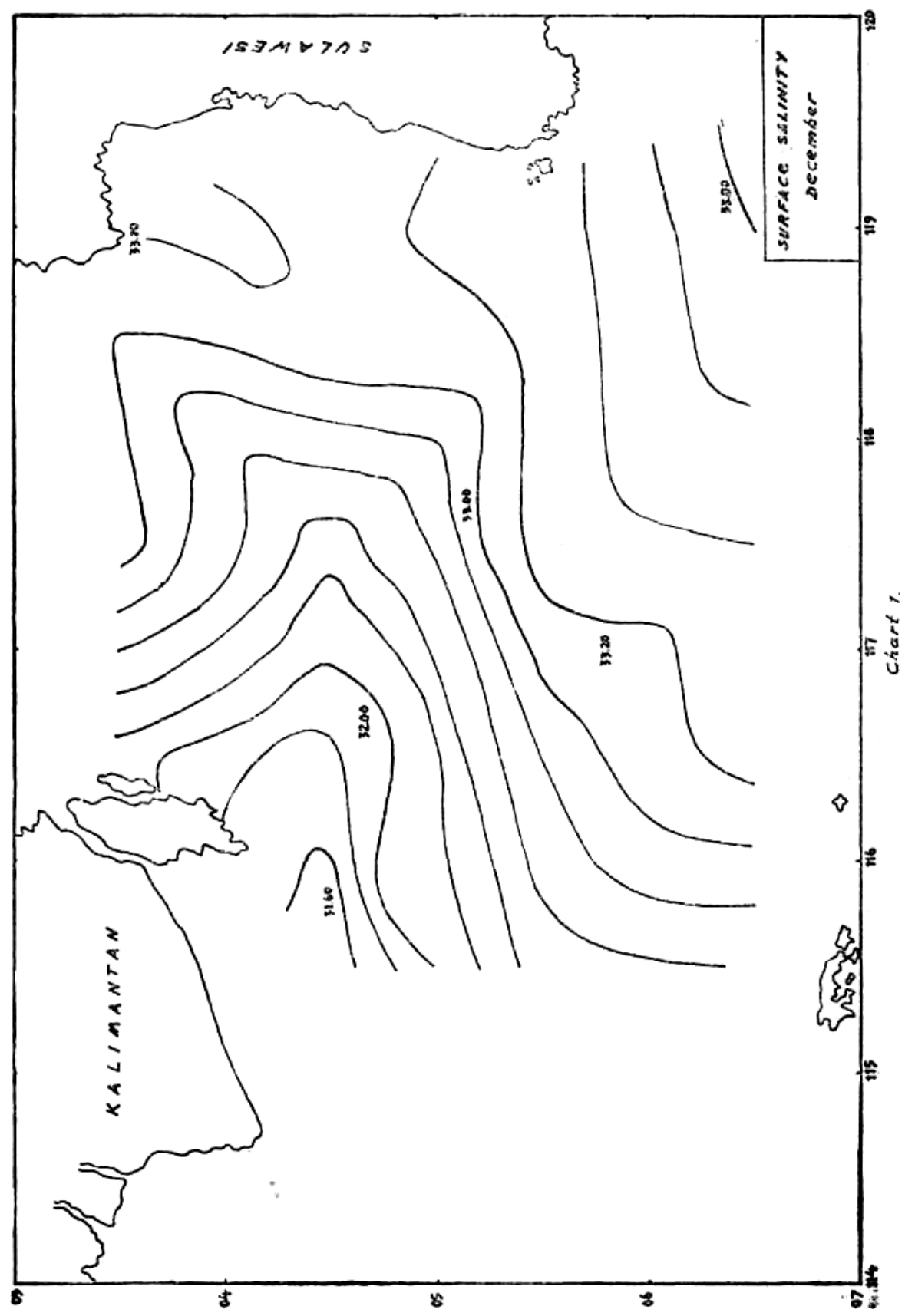




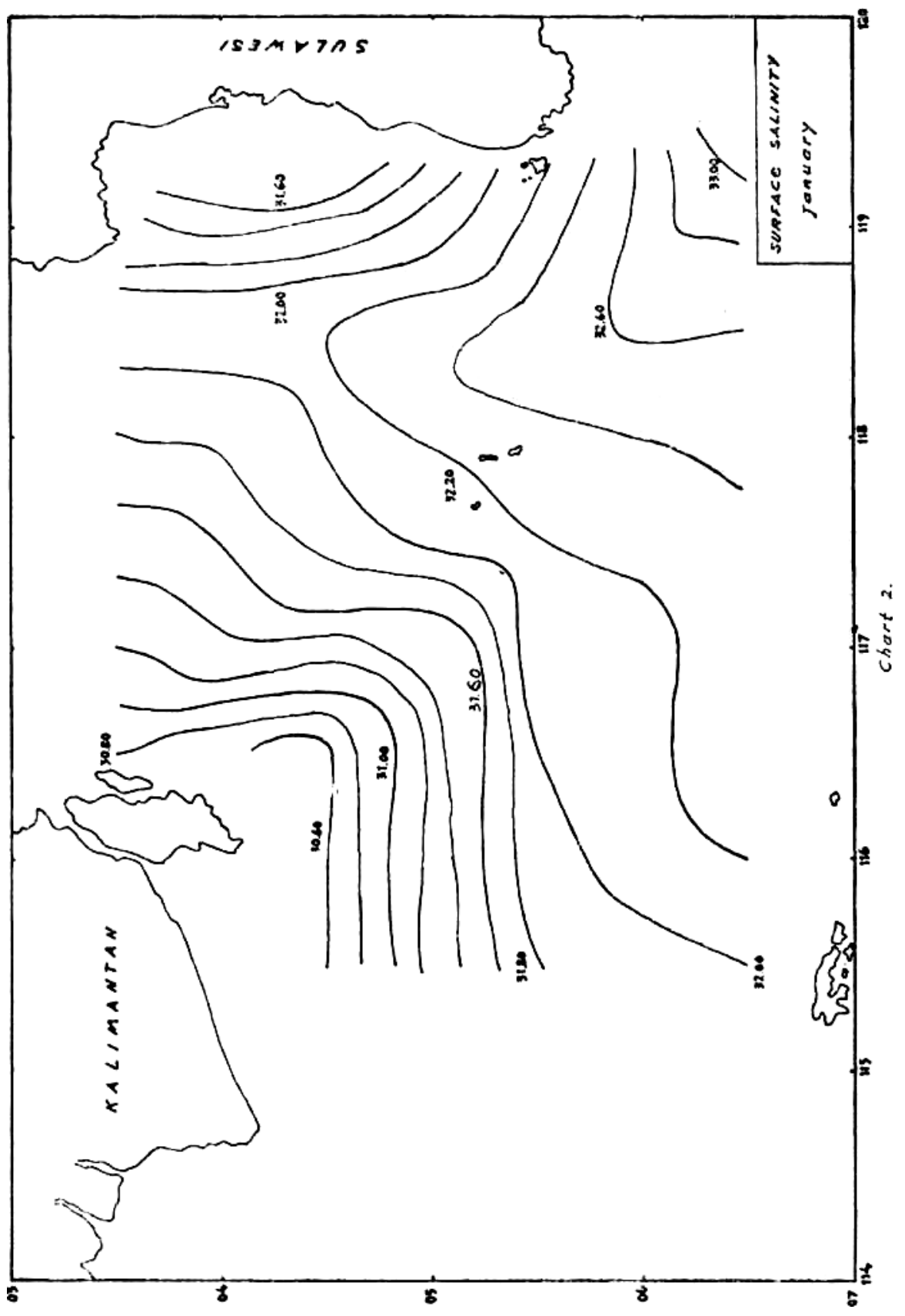




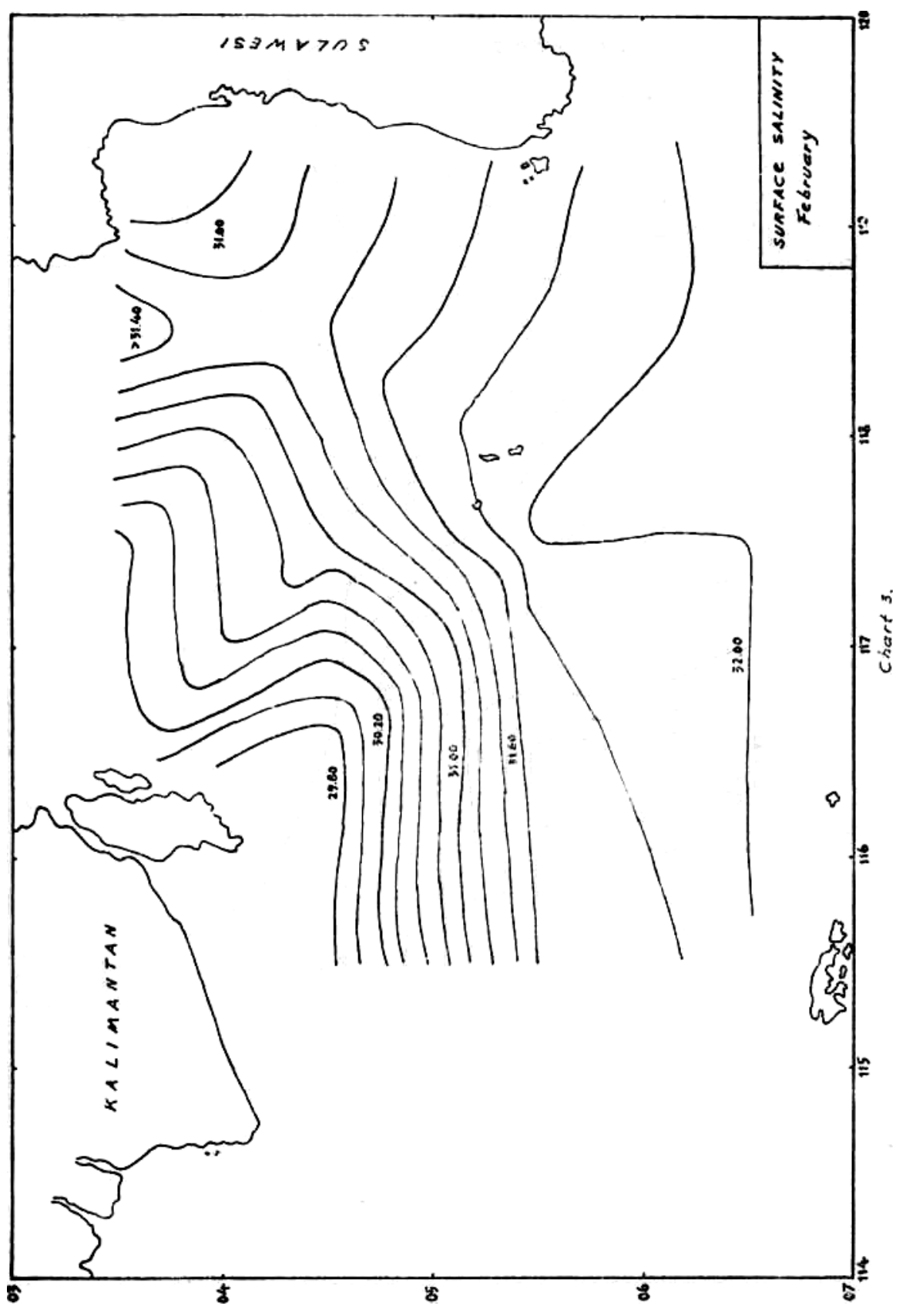




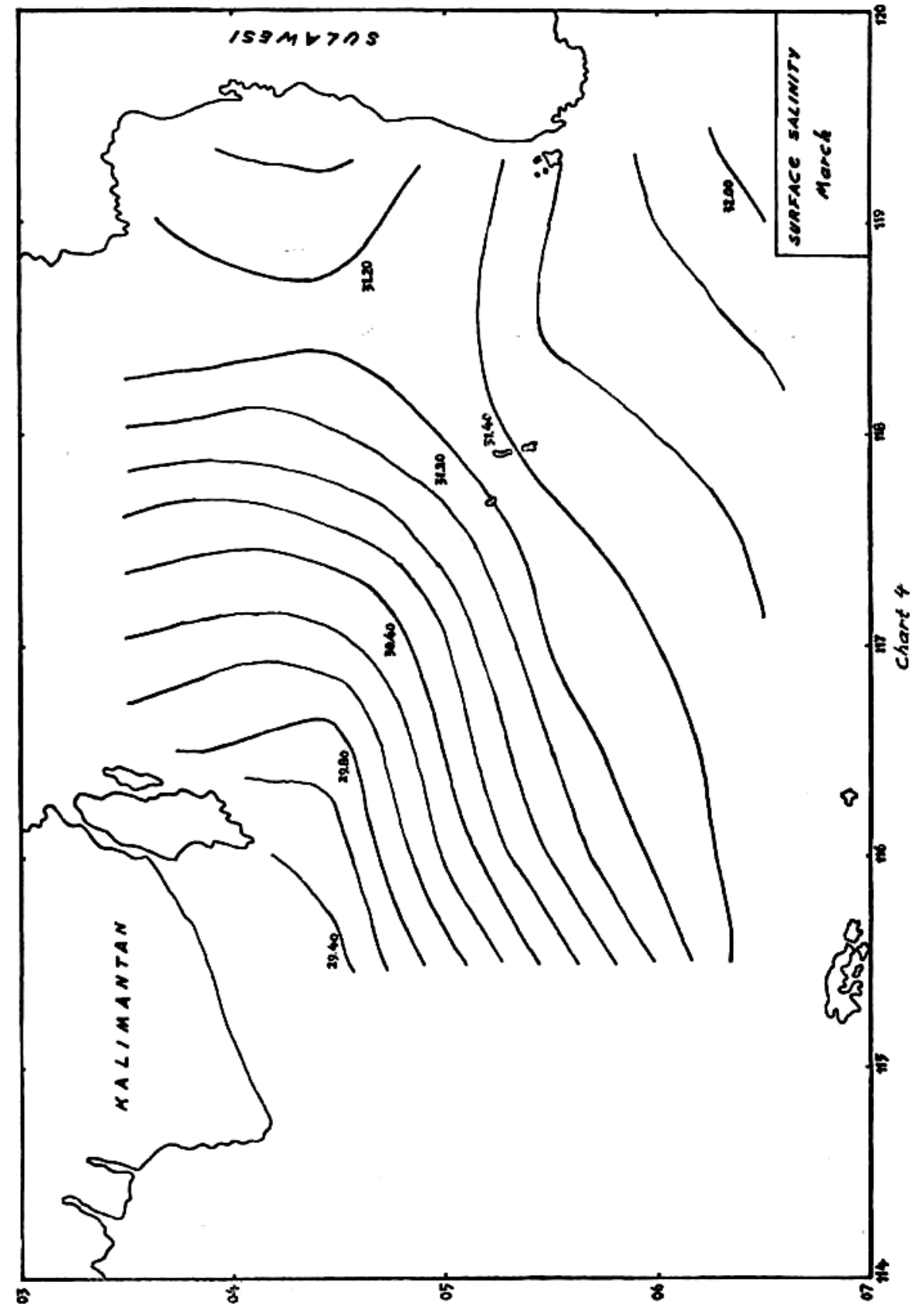




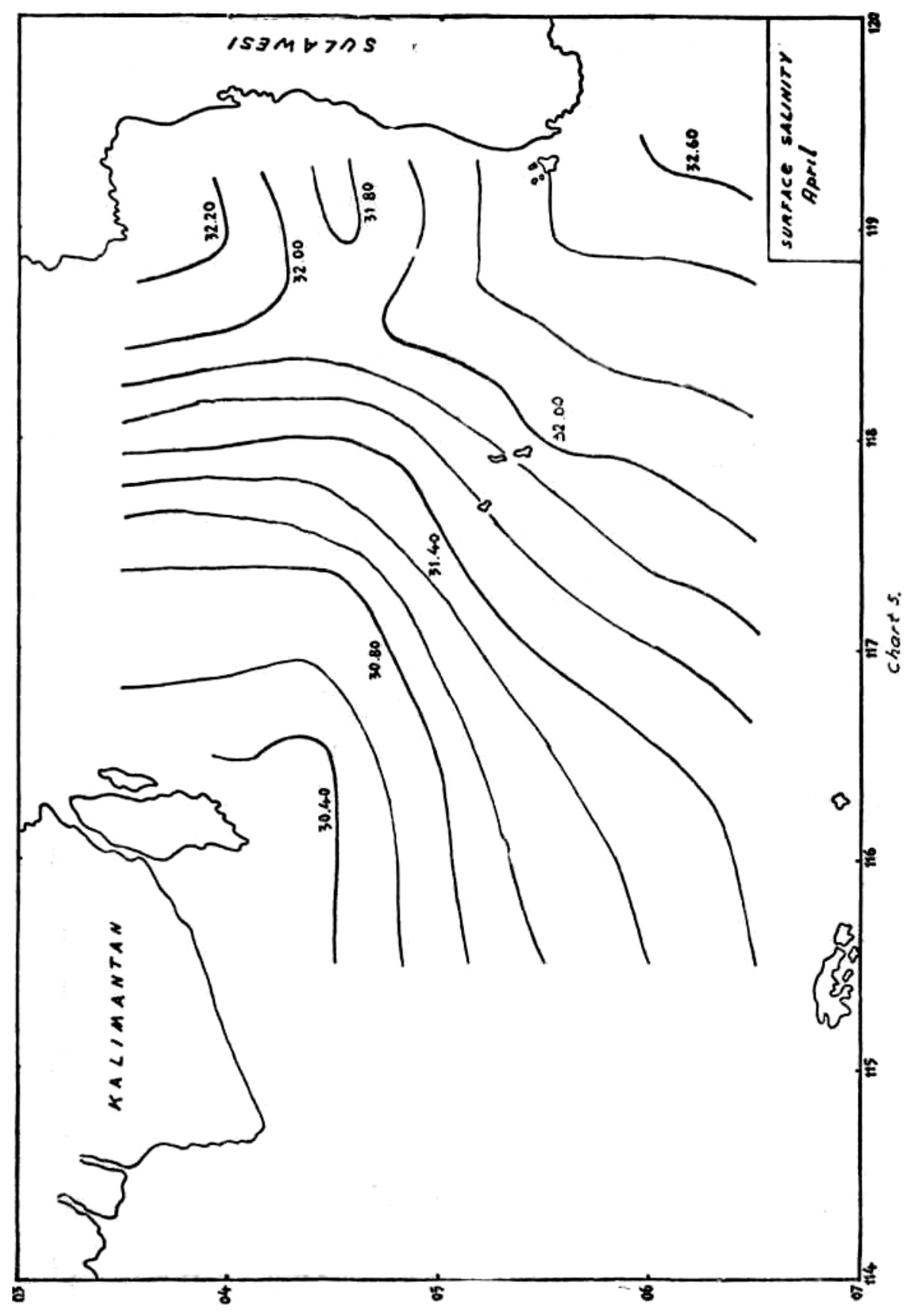




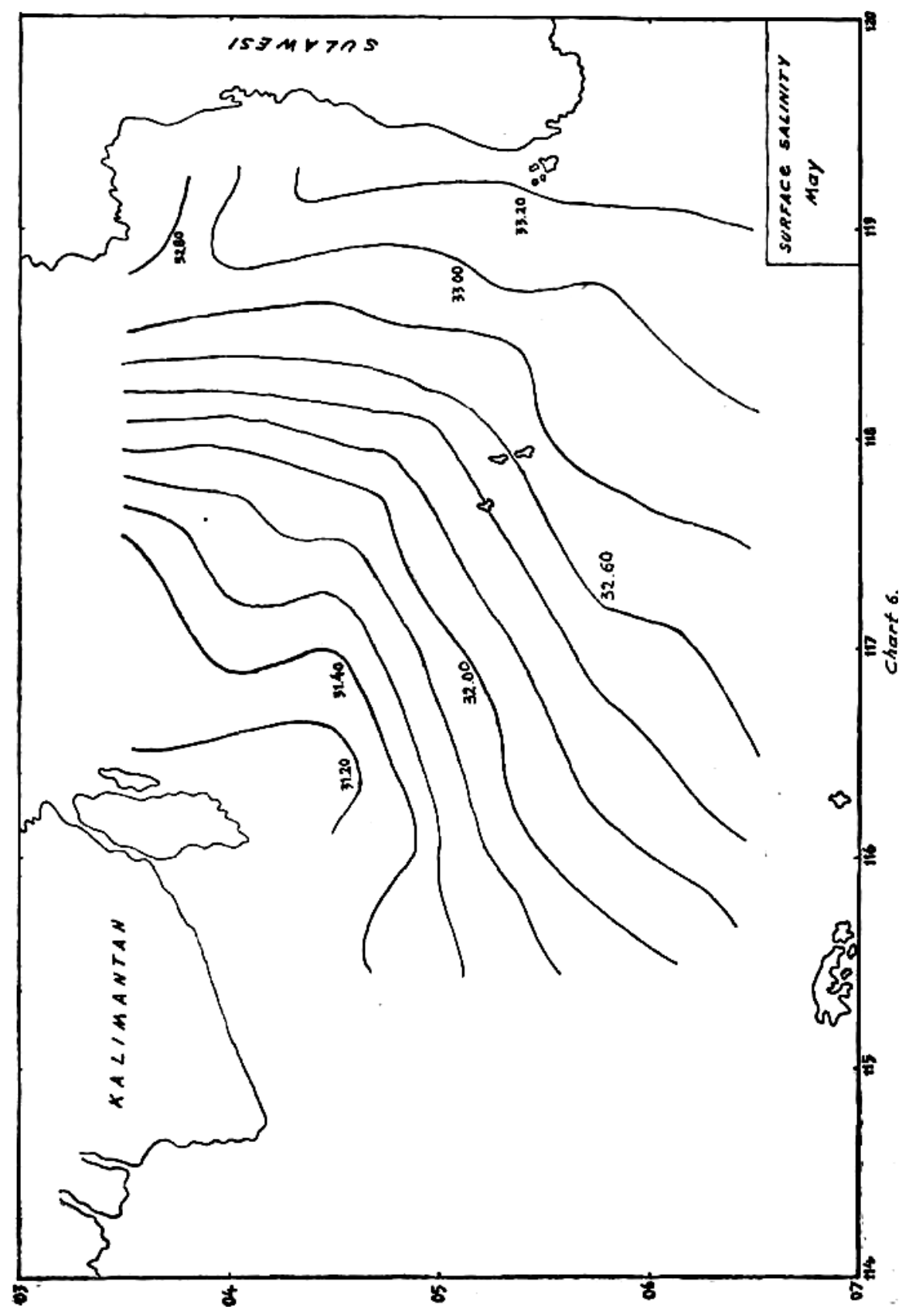









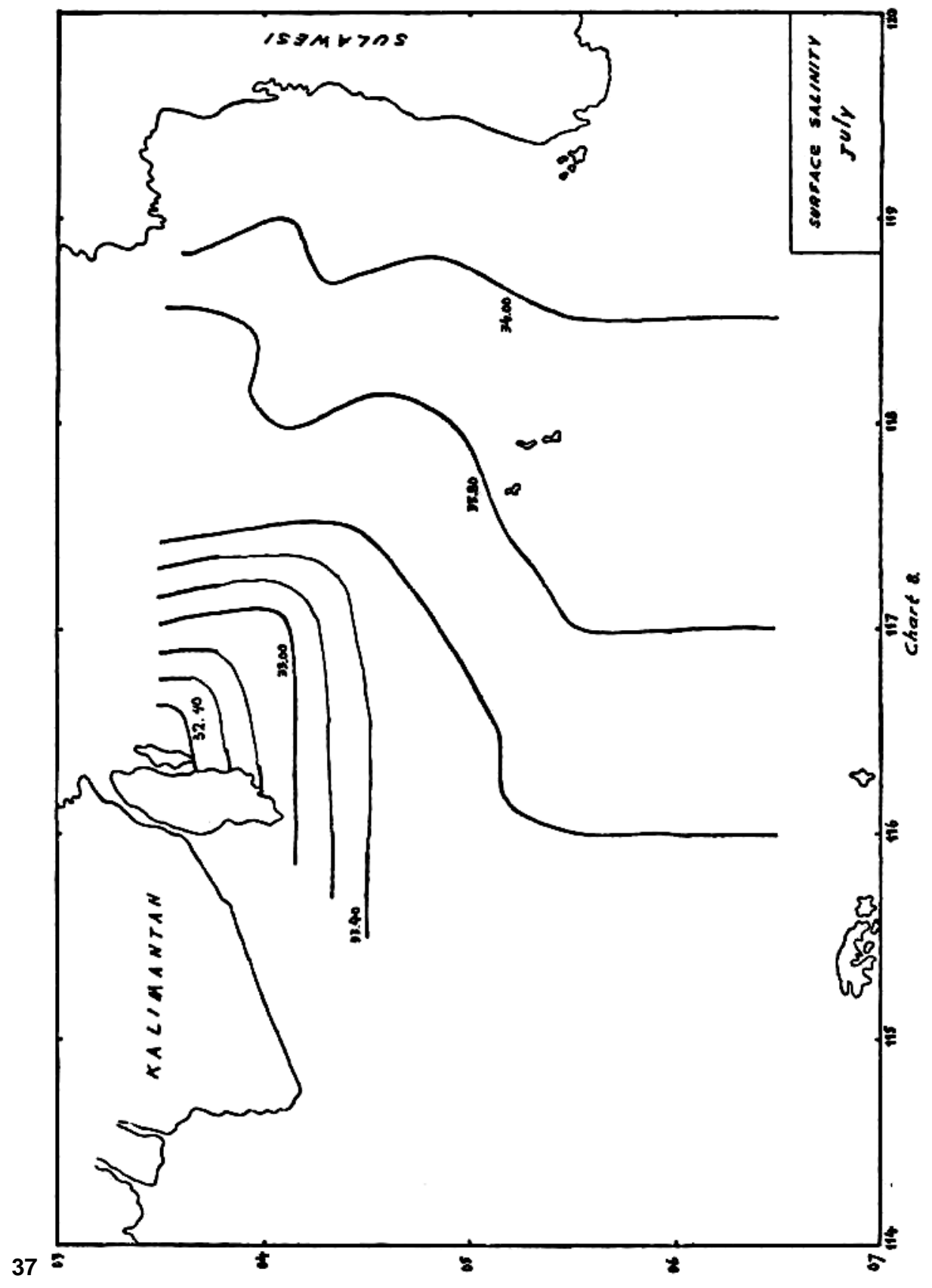




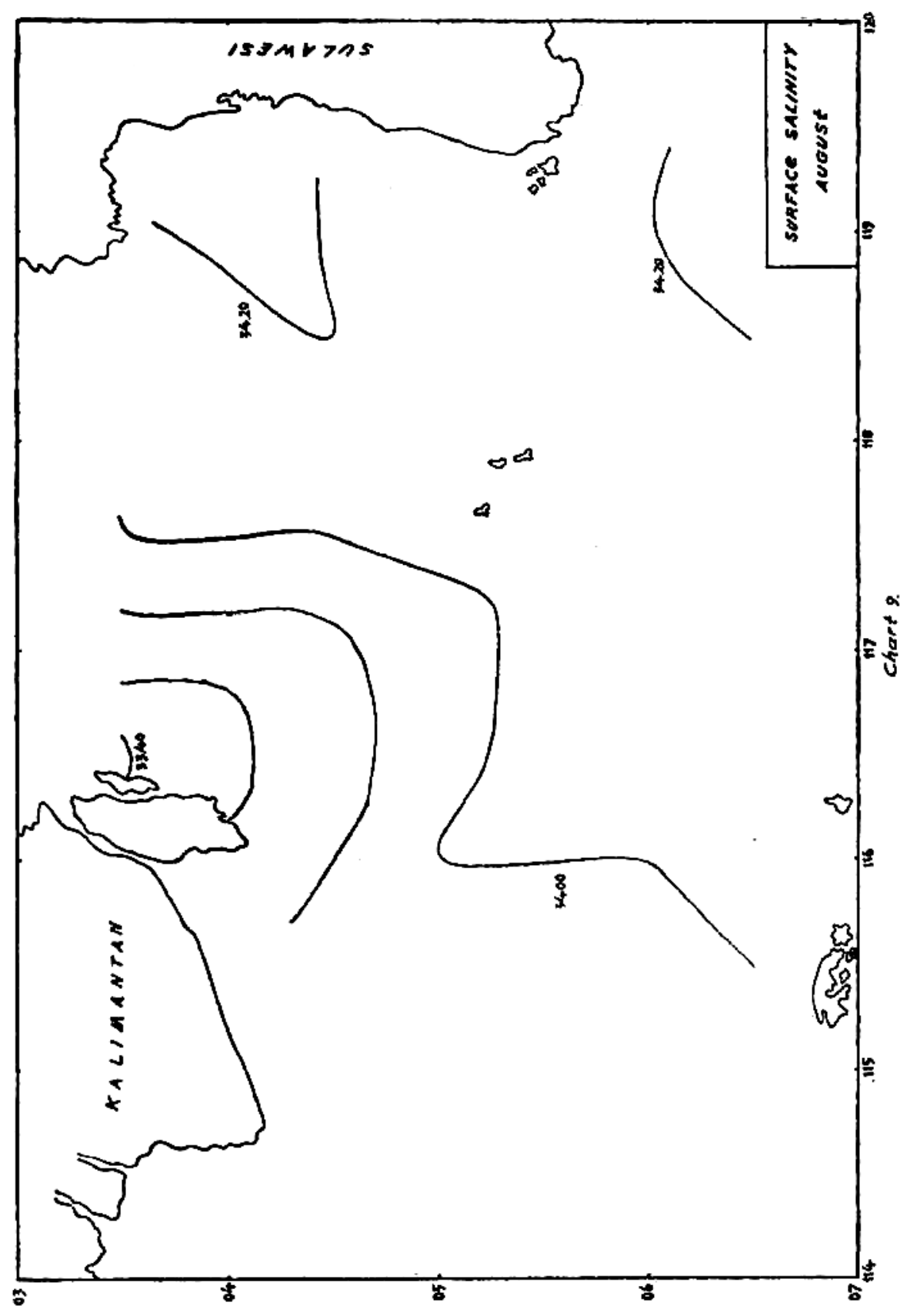




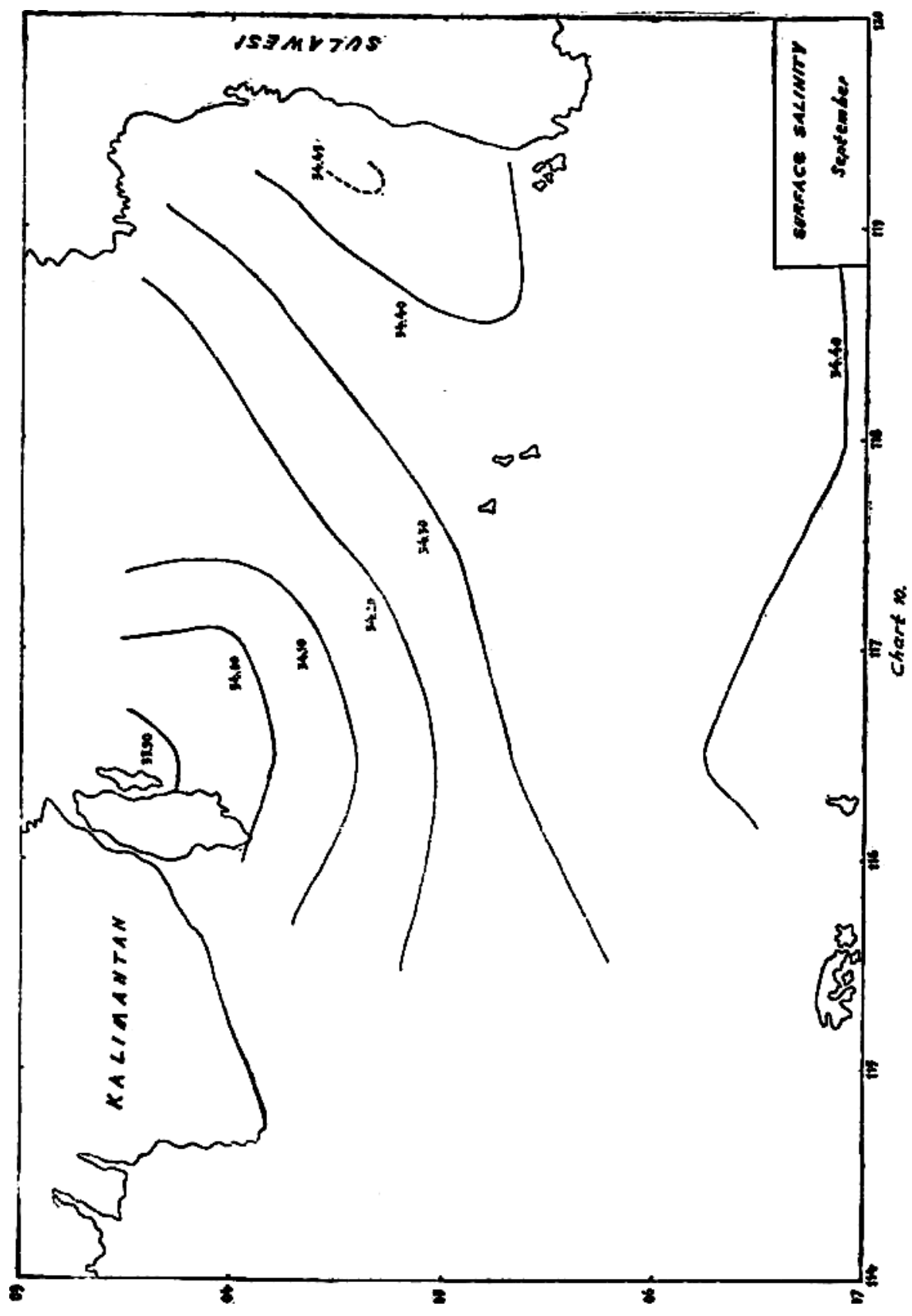




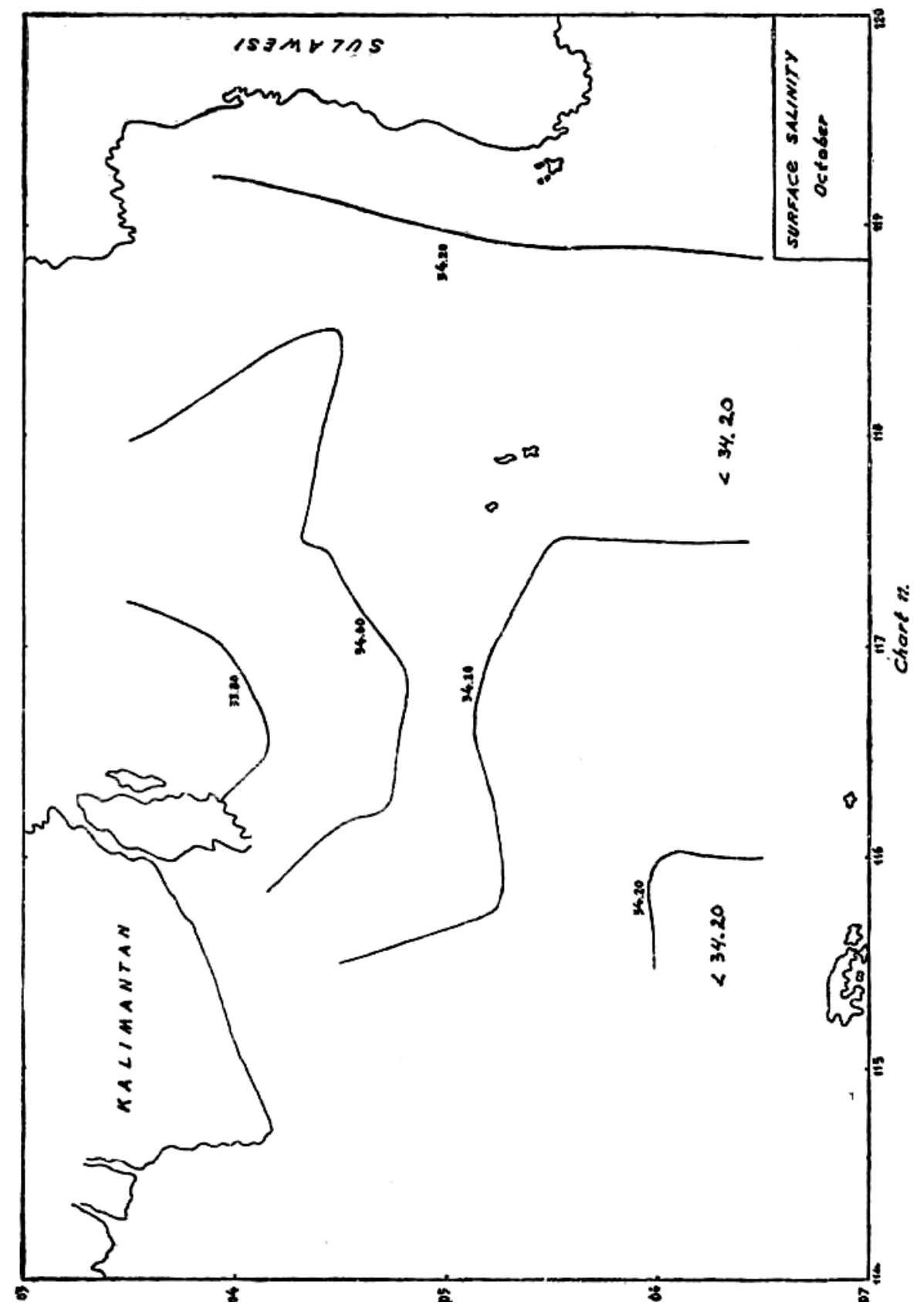




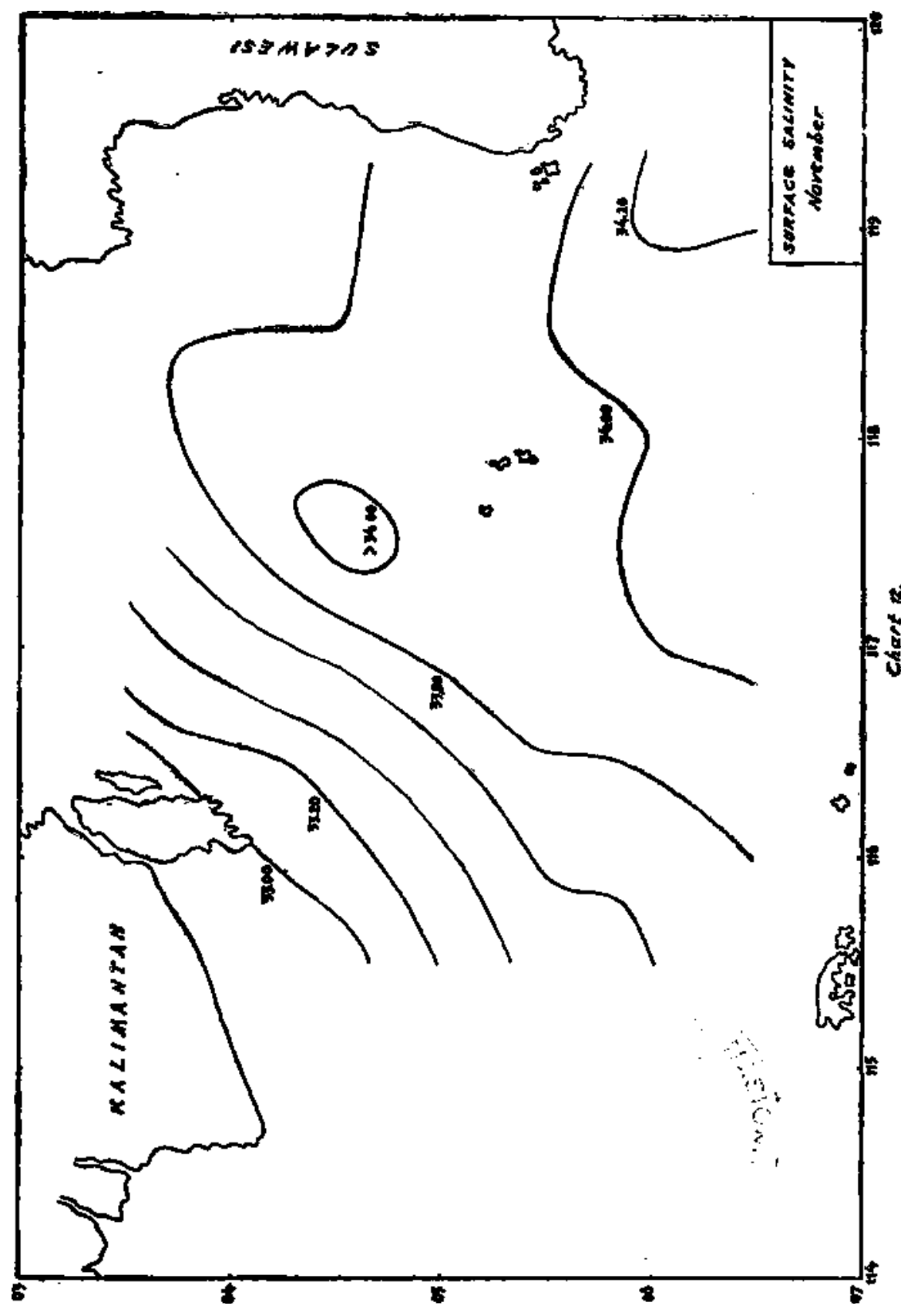




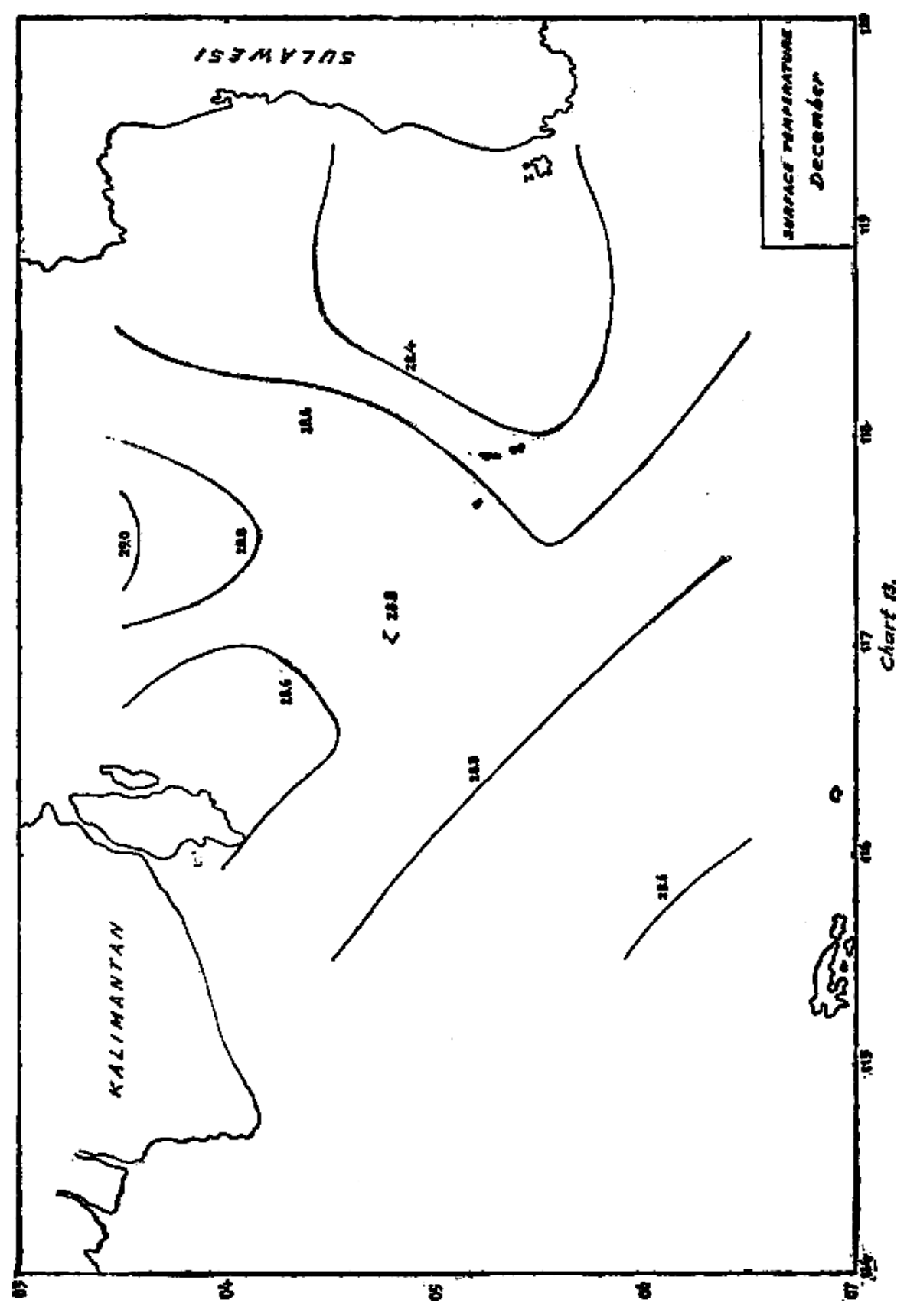




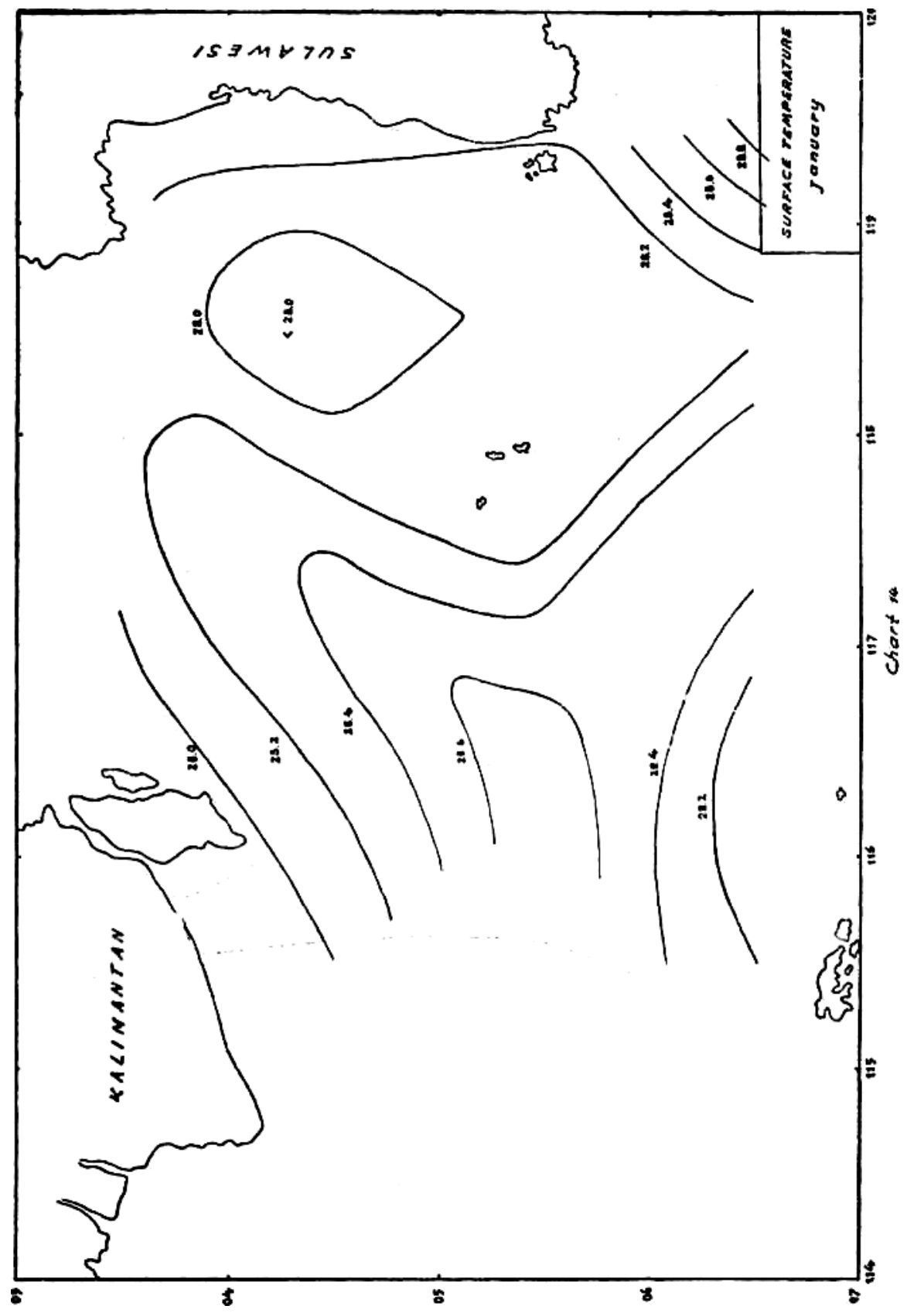




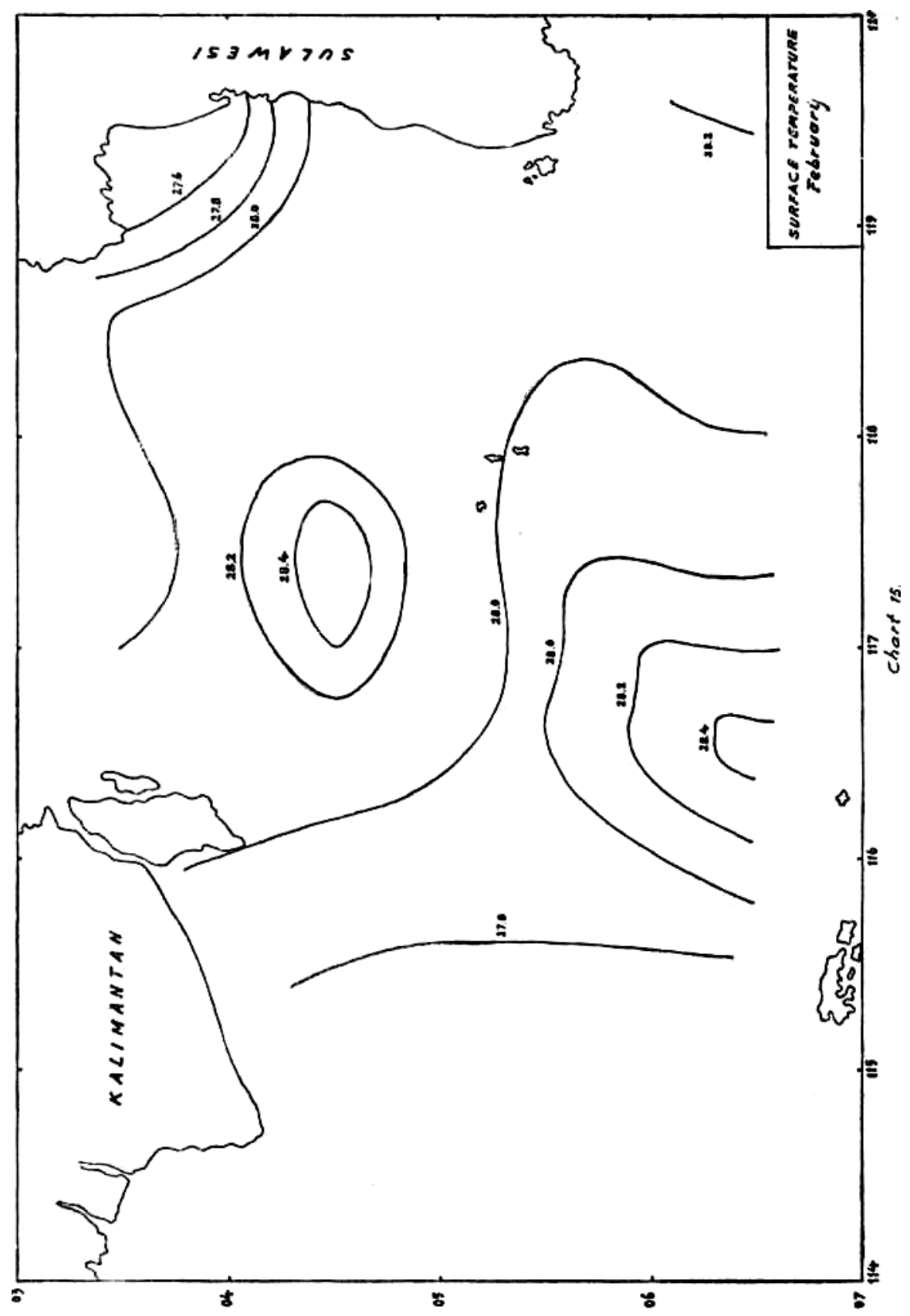




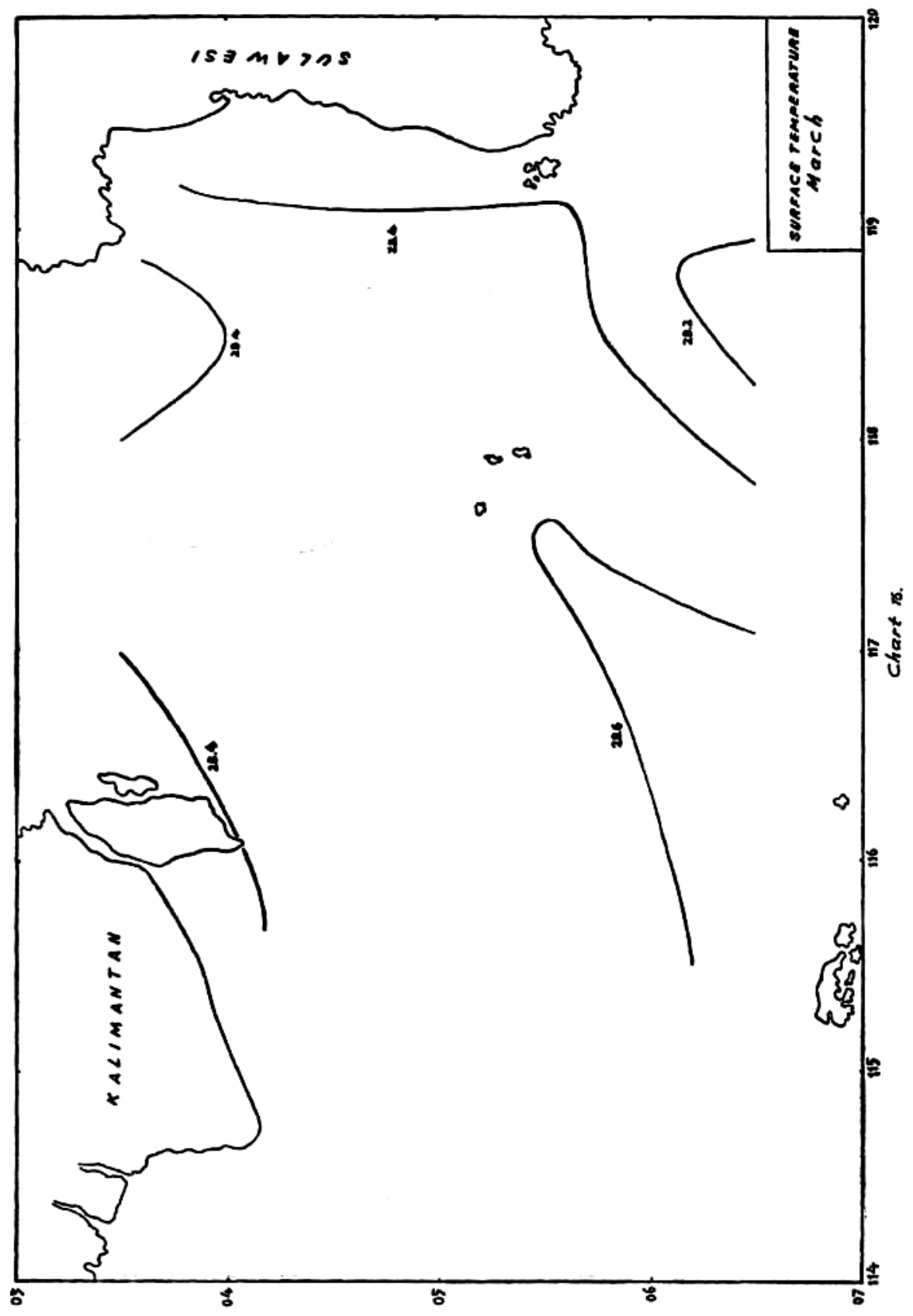




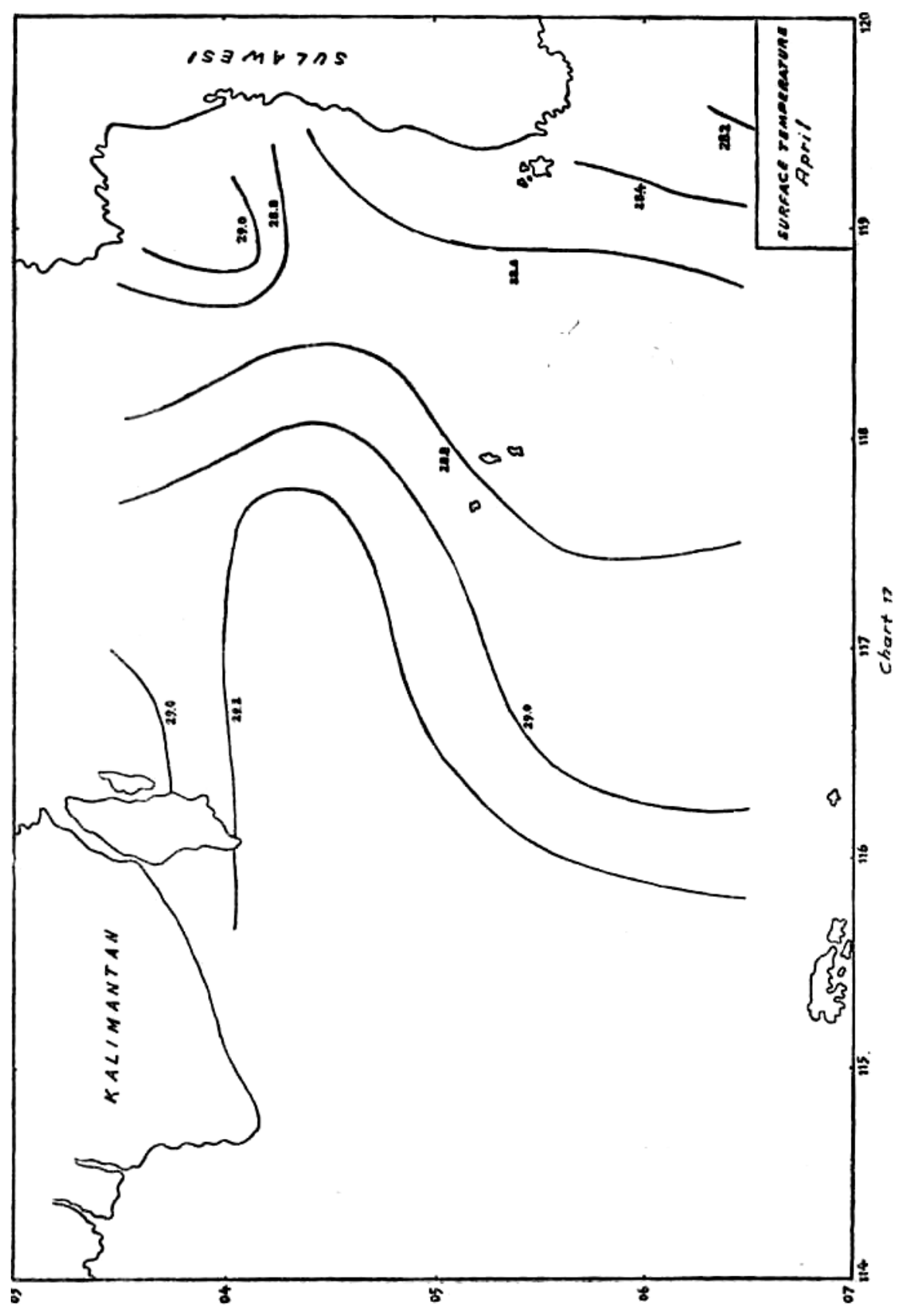




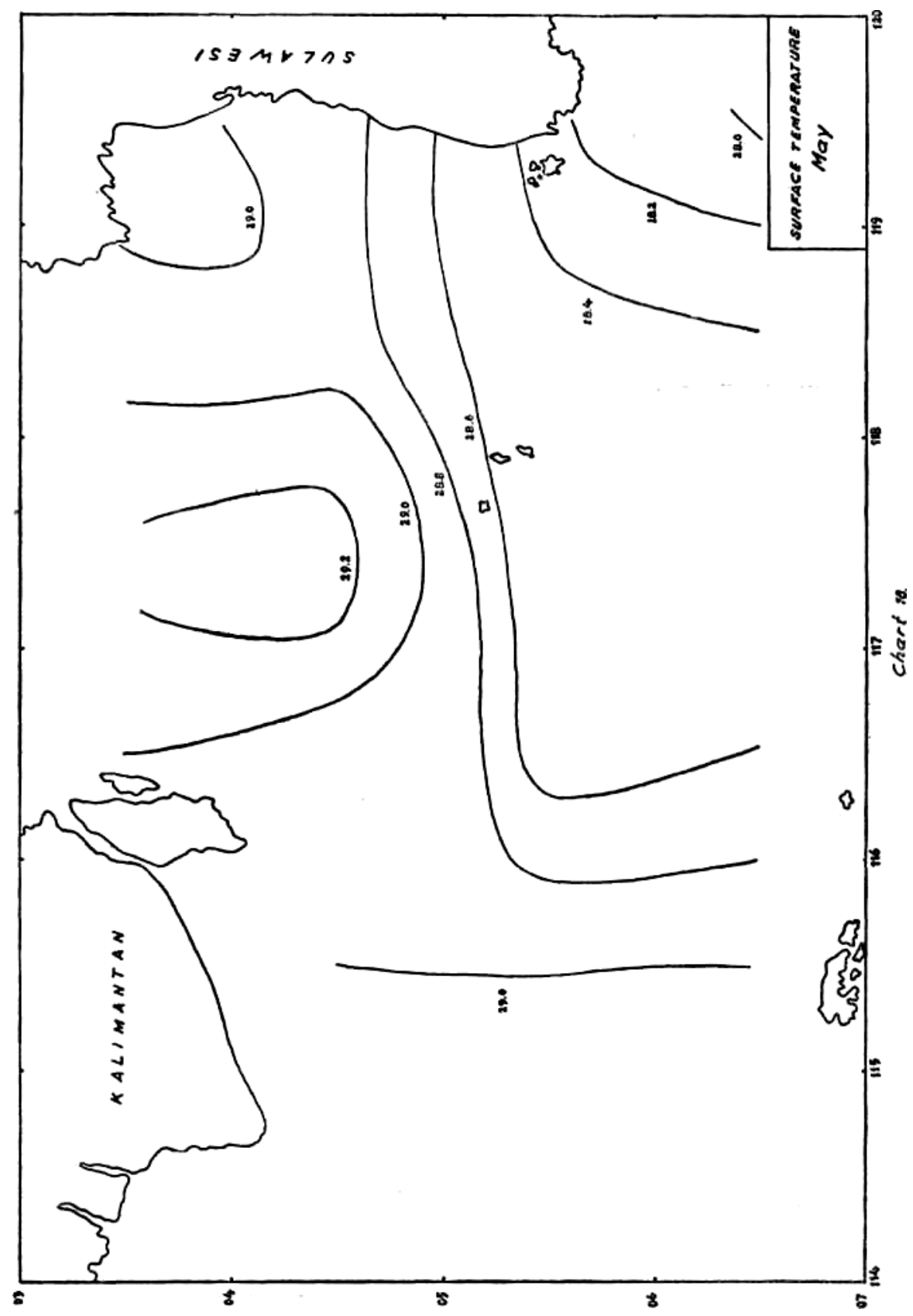




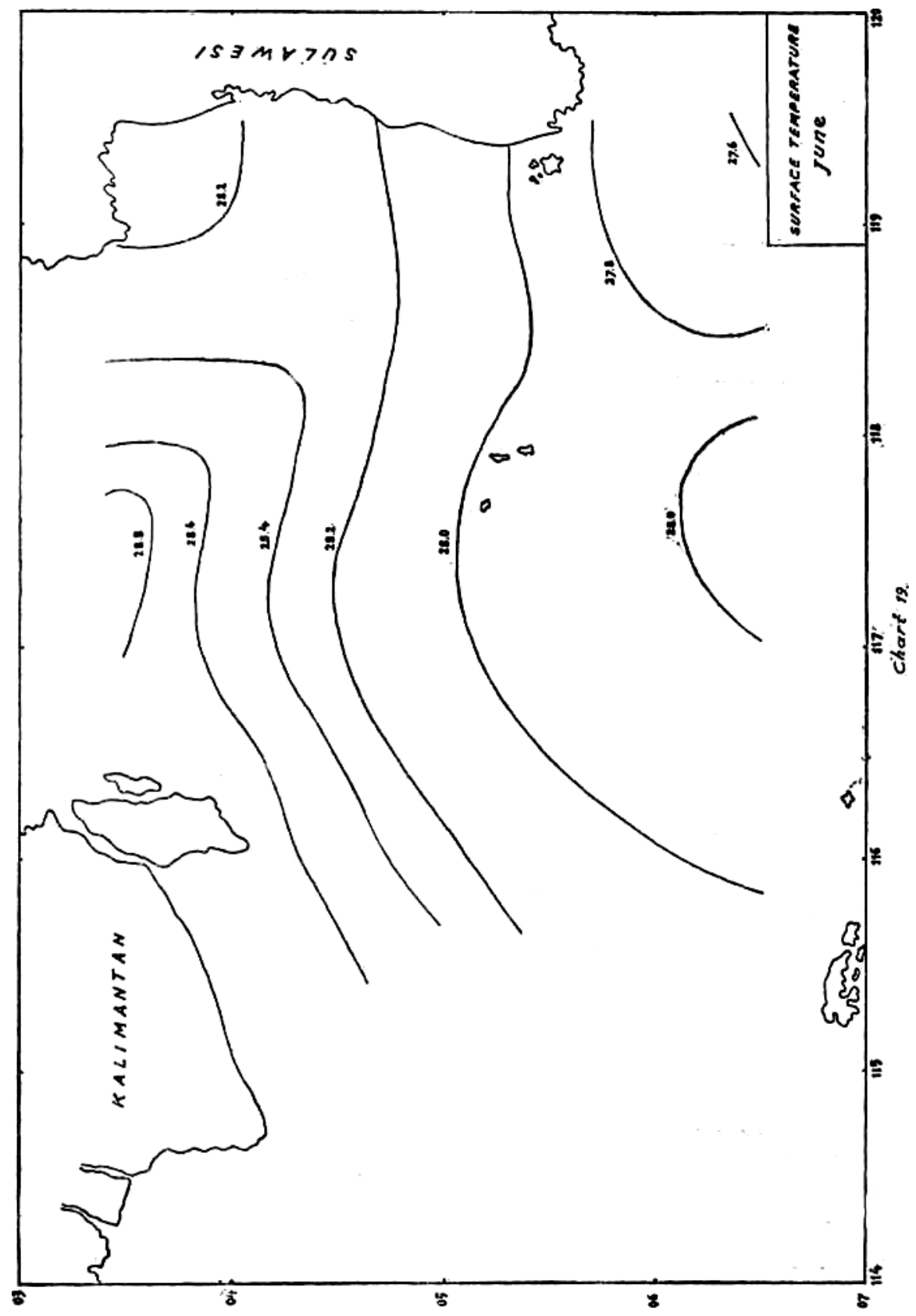




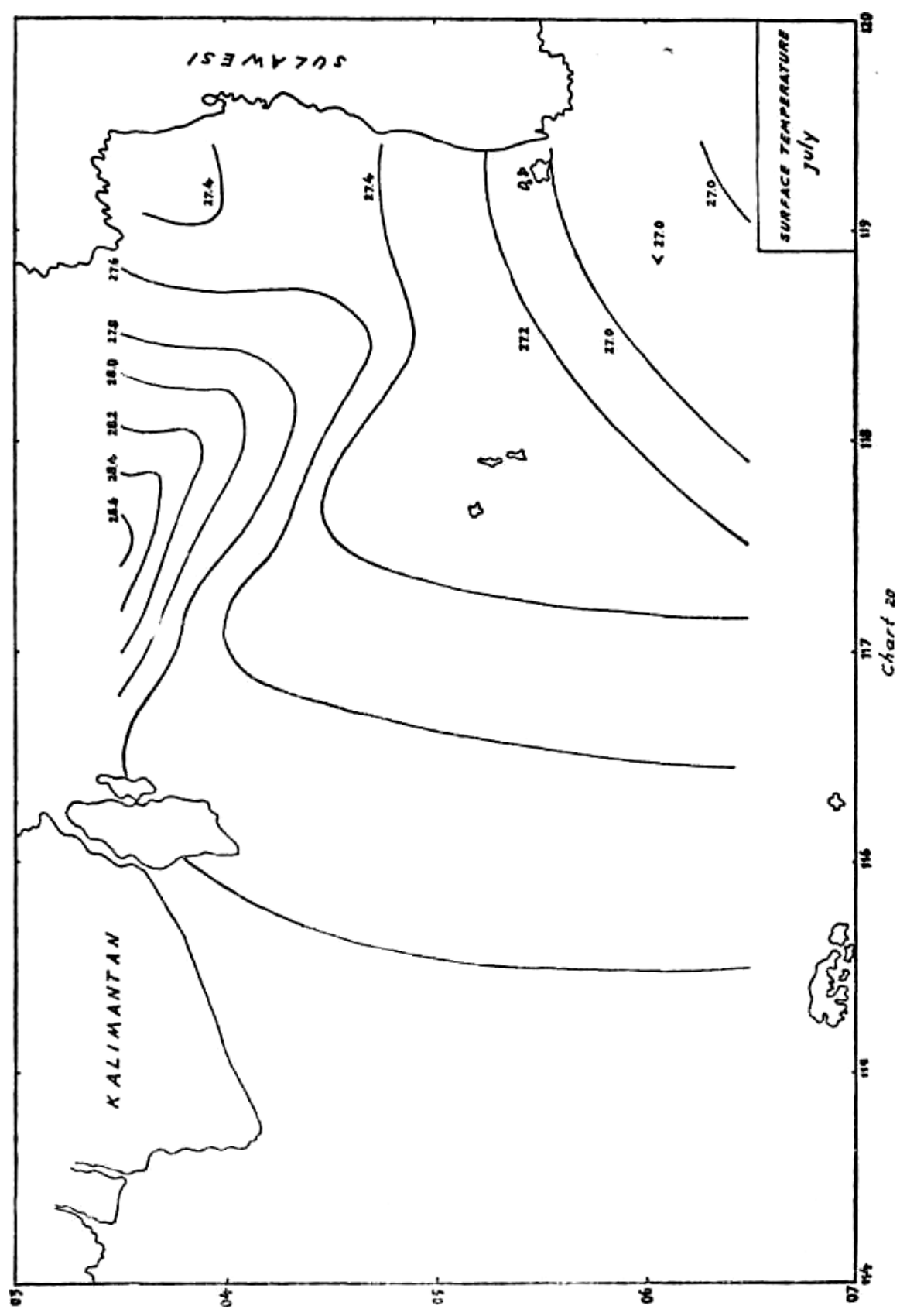




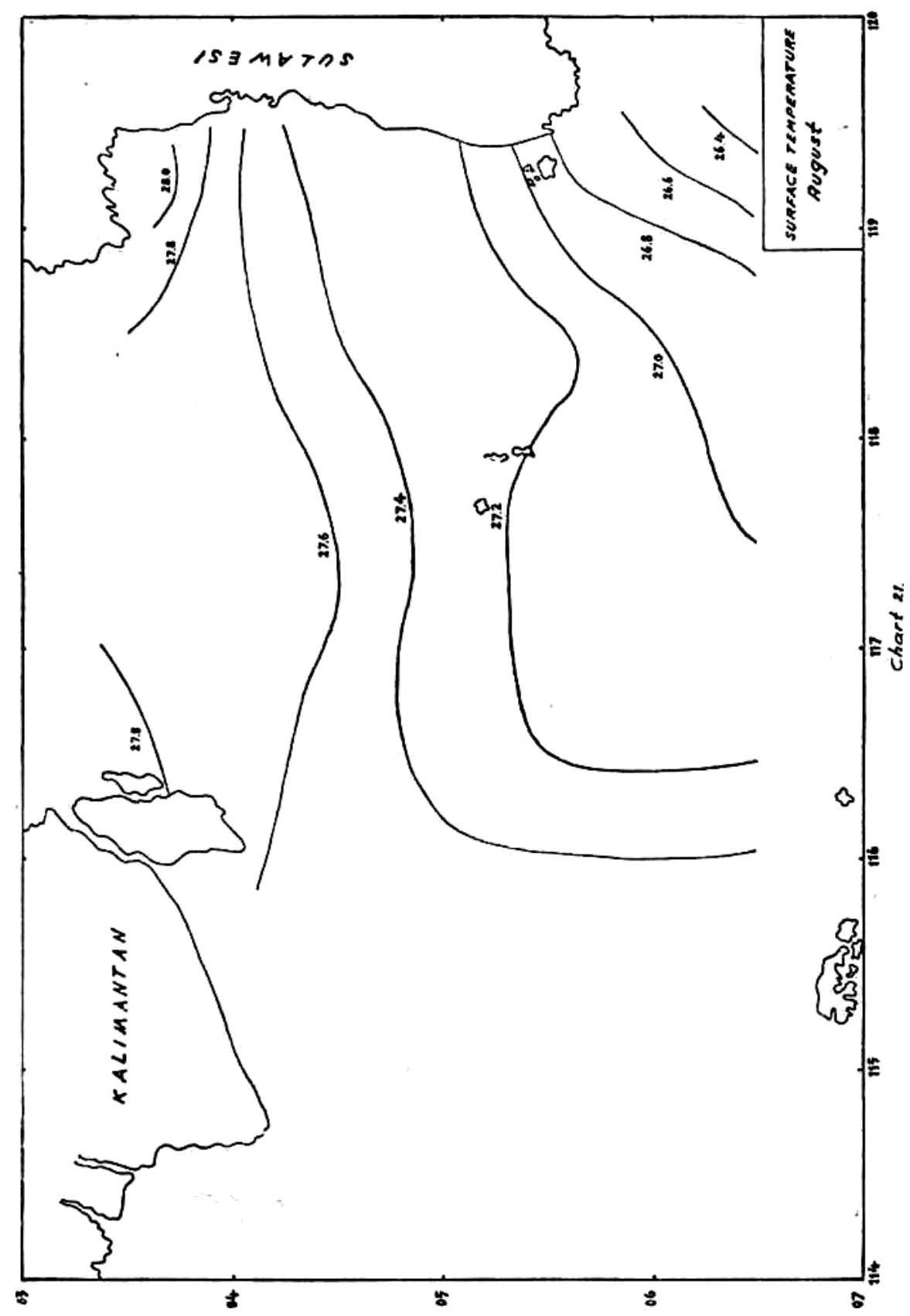




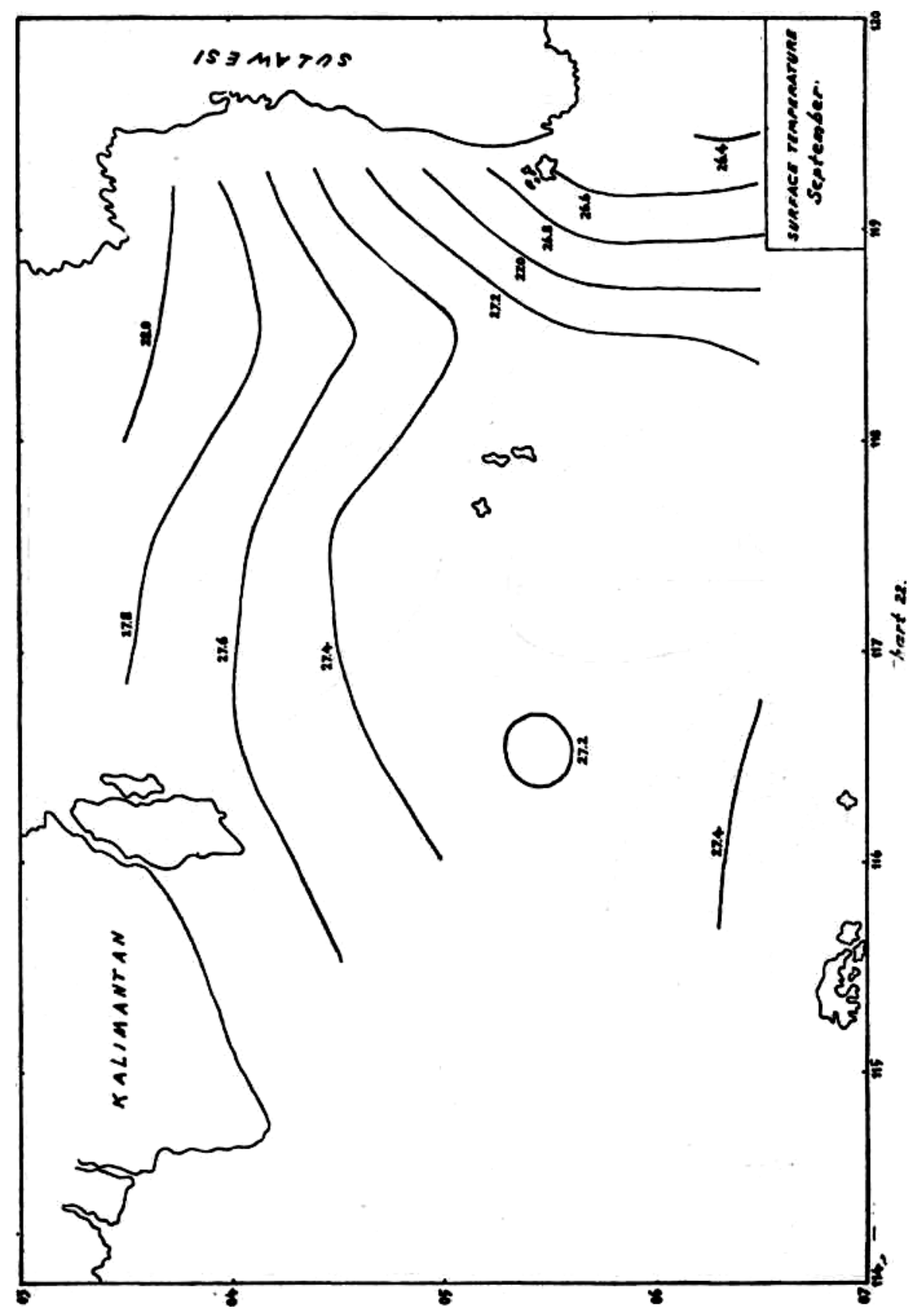




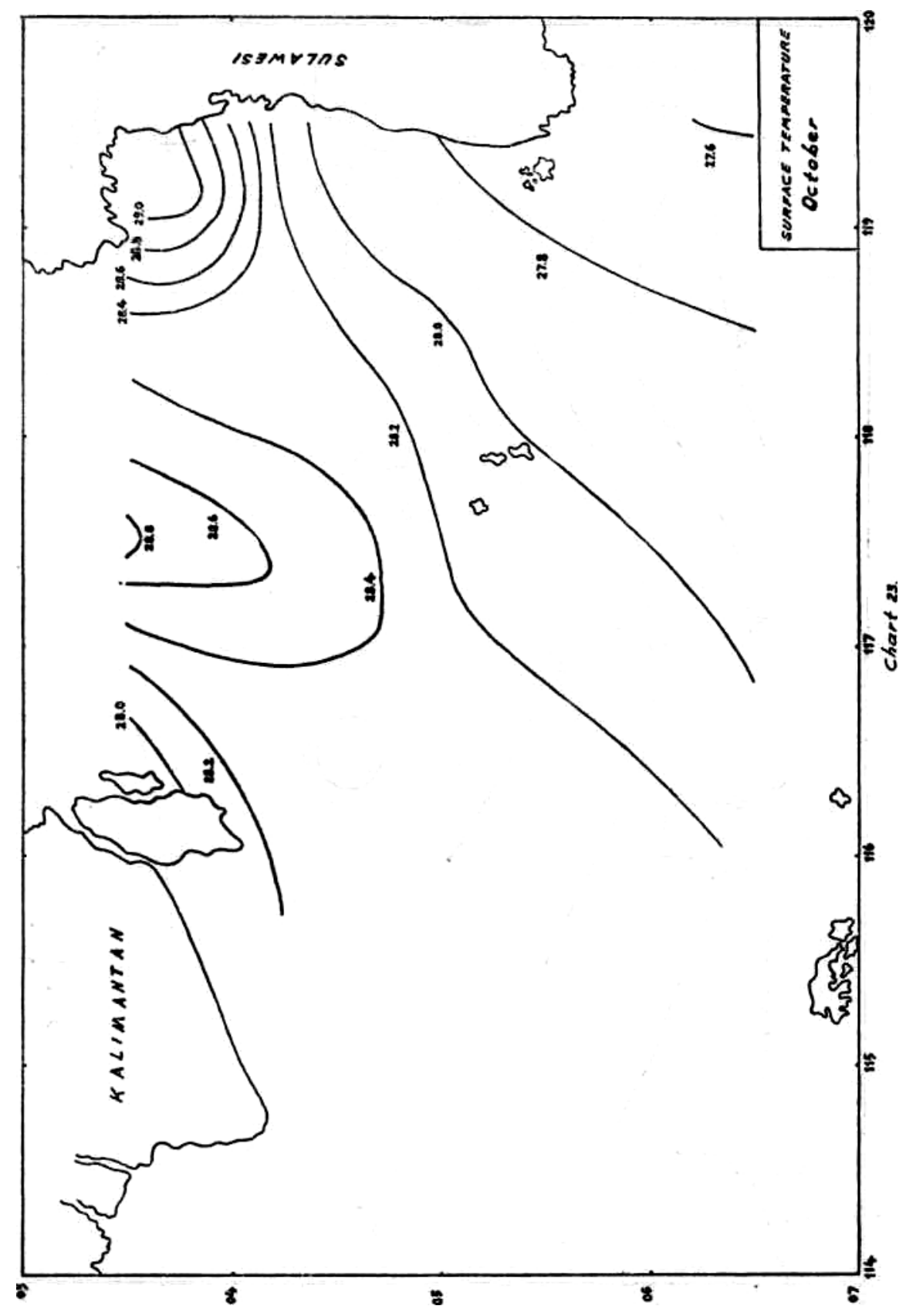




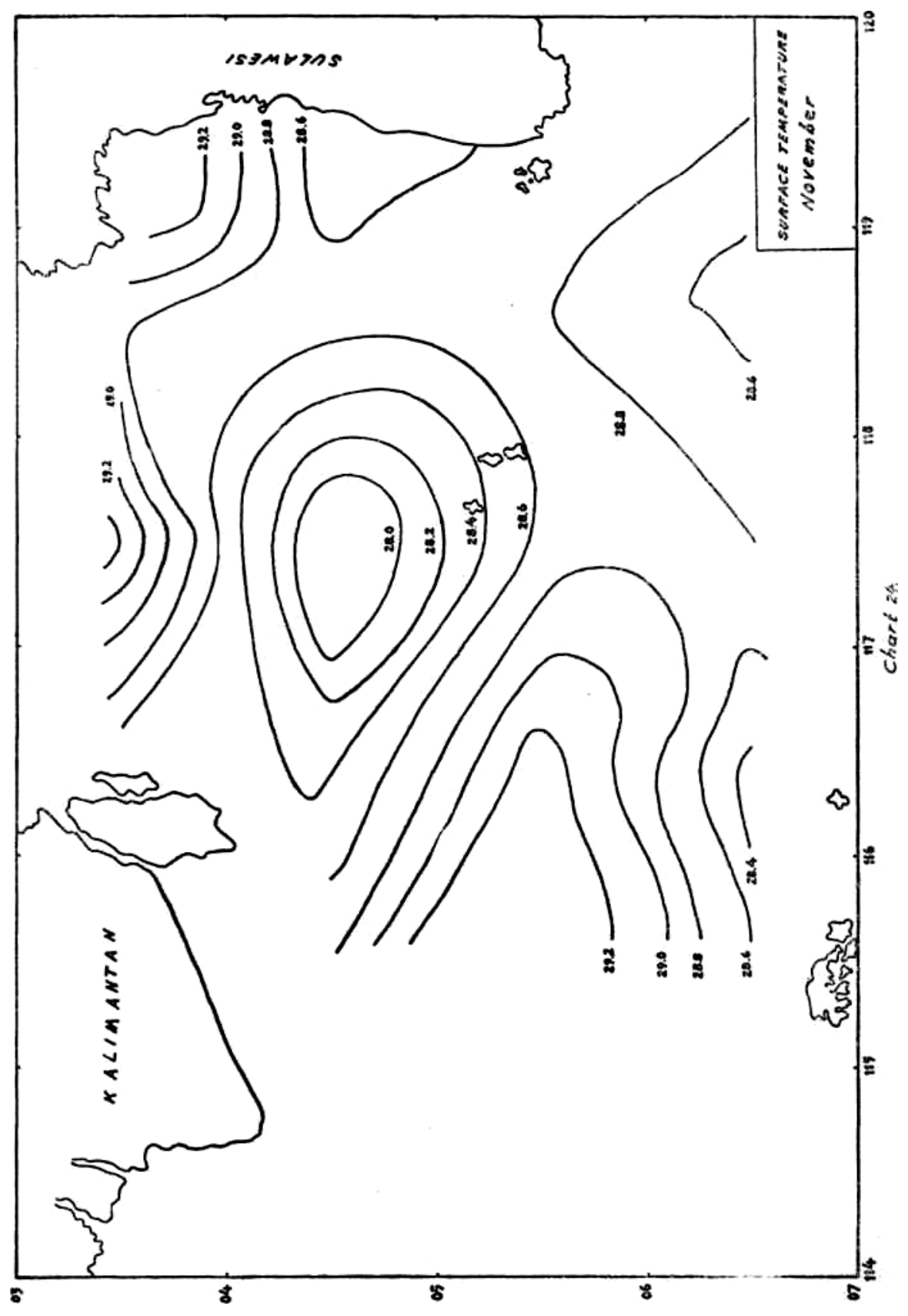

